\title{
WAGE BARGAINING IN INDUSTRIES WITH MARKET POWER
}

A. Jorge Padilla, Samuel Bentolila and Juan J. Dolado 


\title{
WAGE BARGAINING IN INDUSTRIES WITH MARKET POWER
}

\author{
A. Jorge Padilla (*), \\ Samuel Bentolila $(*)$ \\ and Juan J. Dolado (**)
}

(*) CEMFI.

(**) Research Department, Bank of Spain.

Forthcoming in Journal of Economics and Management Strategy. We are grateful to two anonymous referees, and to Víctor Aguirregabiria, Tim Bresnahan, Andea Ichino, Tullio Japelli, Juan F. Jimeno, Andrew Oswald, Marco Pagano, Emmanuel Petrakis and Thomas von Ungem-Stemberg for helpful comments. Participants in seminars at DELTA (Paris), IGIER (Milan), and the 2nd CEPR-European Summer Symposium in Macroeconomics (Tarragona, May 1994) also provided useful comments. We are solely responsible for any remaining errors.

Banco de España - Servicio de Estudios

Documento de Trabajo no 9616 
In publishing this series the Banco de España seeks to disseminate studies of interest that will help acquaint readers better with the Spanish economy.

The analyses, opinions and findings of these papers represent the views of their authors; they are not necessarily those of the Banco de España.

ISSN: 0213-2710

ISBN: 84-7793-489-4

Depósito legal: M. 20867-1996

Imprenta del Banco de España 


\begin{abstract}
In this paper we develop a game-theoretic version of the right-to-manage model of firm-level bargaining where strategic interactions among firms are explicitly recognized. Our main aim is to investigate how equilibrium wages and employment react to changes in various labor and product market variables. We show that our comparative statics results hinge crucially on the strategic nature of the game, which in turn is determined by the relative bargaining power of unions and managers.
\end{abstract}

Keywords: Oligopoly, Strategic complementarity and substitutability, Unions, Wage bargaining.

JEL Nos.: J30, J51, D4. 



\section{INTRODUCTION}

This paper explores the nature of interactions among firms and among unions, when setting wages within an oligopolistic market. Standard models of wage bargaining in industries with market power assume that the product market is monopolistic, thereby abstracting from some interesting interactions between firms and unions that should affect the outcome of collective bargaining. ${ }^{1}$ This is so in spite of numerous pieces of empirical work on the estimation of wage equations at the firm/industry level, where variables such as concentration ratios or market shares are introduced, in a more-br-less adhoc way, as potential explanatory variables connected with market power. ${ }^{2}$ More anecdotal evidence comes from the evolution of industrial relations during the 1980s in the UK, which shows an increasing importance of company performance for wage setting. Commenting on this evolution, Metcalf (1993, p. 279) states: "Nowadays the link between the product and labour markets would be central to any investigation. It is largely because of this connection that the industrial relations system has evolved in such a way that it can no longer stymie company performance. Any such lack of performance can no longer be laid at the door of the unions."

In response to that deficiency in the modeling of wage bargaining, there have been in recent years several attempts to properly analyze strategic interaction effects in unionized oligopolistic industries. To our knowledge, the first study to do so is Davidson (1988), where the relationship between bargaining 
structure and wage outcomes in unionized industries is studied using noncooperative game-theoretic results. Around the same time, in independent work, Dowrick (1989) used the conjectural variations framework in oligopoly models to study how product market power and profitability relate to wages. In particular, his paper focuses on how the effects of union coordination on wages depend on the bargaining situation, namely, whether bargaining is over wages and employment or just about wages. More recently, further work by Dowrick (1993), Dowrick and Spencer (1994) and Santoni (1994), using slight variations of the previous models, analyze various topics of interest, like the attitude of unions towards labor-saving innovations, the relative degree of aggressiveness of enterprise and craft-based unions, or the strategic effects of international trade on domestic wage setting.

These papers are, however, developed under the assumption that unions at different firms all have the same bargaining strength, and that all firms have access to the same production technology. In this symmetric setting, it is impossible to characterize the impact of changes in a firm's bargaining scenario (defined by the bargaining strength of the union operating at that firm, the firm's technology, and the characteristics of the product and labor markets in which the firm operates) on its counterparts. Most importantly, these papers exclusively focus on settings where the strategic nature of the game is such that an increase in a firm's wage unambiguously raises its competitors' wages, a feature which can be shown to bias their results in several instances.

The model in this paper overcomes the problems just cited. It is a static model of firm-level bargaining in a duopolistic industry selling differentiated 
products, where firms are all unionized, but where the unions' bargaining power differs from one firm to another. To simplify the exposition of the main results, we take a number of shortcuts. First, we develop an asymmetric version of the right-to-manage model of firm-level wage bargaining, where the choice of employment is left to the firm, since this seems to be a reasonable assumption on empirical grounds. ${ }^{3}$ Second, we concentrate directly on the non-cooperative Cournot-Nash equilibrium of the two uniontwo firm structure, rather than on the encompassing conjectural variations framework. ${ }^{4}$ Third, we make a number of simplifying assumptions, like the use of linear demand functions and uniformly distributed demand shocks. On the other hand, these simplifications allow us to introduce more complexity along other key dimensions (uncertainty in demand, more general union preferences), thus generalizing what is found in the previously cited papers, and thereby enriching the model's predictions.

Under the previous assumptions, we show that unions are more likely to press for wage increases at the bargaining table when their fellows at competing firms enjoy higher wages, which is a well-established empirical fact. ${ }^{5}$ The reason is that each union recognizes that higher wages at rival frrms lead to a more favorable competitive standing in the product market for its own firm and, therefore, a lower risk of layoffs for a given wage increase. By the same token, from the viewpoint of managers, an increase in the rival's wage raises the marginal desirability of a wage cut. The reason being this time that, under a wage rise in the rival firm, it becomes easier to gain market share, which in addition becomes more valuable as the price-cost margin also increases. Thus, in the now standard terminology introduced by Bulow et 
al. (1985), wages are strategic complements from the unions' point of view, whereas they are strategic substitutes for managers.

Given the previous result, it is clear that the overall strategic nature of the game (i.e., whether the overall game is one of the strategic complements or substitutes) depends on the relative power of unions and managers at the bargaining table. Moreover, it can be shown that the results from the comparative statics analysis of how wages respond to changes in various dimensions of the labor and product markets (like the level of unemployment benefits or the degree of industry concentration) depend crucially on that strategic nature. For instance, take the effect of an increase in the bargairing strength of a union on the wages of both firms: if the game is one of strategic complements, wages will increase in both firms, whereas if it is one of strategic substitutes, the own firm's wage will increase but the other firm's wage will decrease. These effects have largely been ignored in the existing literature because of the (implicit) assumption that the relative bargaining power of unions and managers is such that the game features strategic complements, thereby finding that increasing the bargaining power of one firm's union power unambiguously raises wages in all firms.

The different viewpoints of managers and unions regarding the strategic nature of wages also have implications for the determination of the bargaining structure at the industry level and the negotiation outcomes. On this score, we not only derive similar results to those found in Davidson (1988) and Dowrick (1989), but also give a natural interpretation of why unions are more likely to coordinate their wage claims than firms' managers, as happens in many countries. 
The rest of the paper proceeds as follows. Section 2 describes our duopoly model and solves for equilibrium wages and employment. Section 3 presents comparative statics results and develops intuitions for them. In section 4 we extend the model of the previous sections to study the relationship between market power and wages and the role of competition policy to moderate wage inflation (section 4.1); and also compare the outcomes of wage bargaining with firm-level unions and industry-wide unions (section 4.2). Section 5 draws some concluding remarks.

\section{THE MODEL}

\subsection{THE BASIC SETUP}

This is a static model of firm-level bargaining in a duopolistic industry, where competing firms are all unionized and demand is ex ante uncertain. We assume for simplicity that there is a single union and a single manager per firm. Managers and unions are all risk-neutral, maximizing their own expected payoffs. At each firm, wages are bargained over ex ante, taking as given the competitor's wage, considering their impact on the product market equilibrium outcomes. Employment levels, instead, are decided ex post by managers alone. They set employment (or, equivalently, production) simultaneously and non-cooperatively to compete for the demand for a good which may be differentiated according to brand name and/or quality (i.e., the interaction in the output market is Cournotian). ${ }^{6}$

-The product market: Firm $j$ faces an inverse linear demand function 
equal to $p_{j}=f(Q, \theta)+v_{j}=\theta-Q+v_{j}(j=1,2)$; where $p_{j}$ is firm $j$ 's price, $\theta$ is a common demand shock distributed uniformly on the interval $[\underline{\theta}, \bar{\theta}]$, where $q_{j}$ denotes firm $j$ 's output, $Q=q_{1}+q_{2}$, and $v_{j} \geq 0$ measures the consumers' willingness to pay for brand $j$ (which we take to be positively related to firm $j$ 's R\&D effort, and advertising and marketing expenditures).

Firms use only labor to produce according to the production function $q_{j}=a_{j} N_{j}$, where $N_{j}$ denotes firm $j$ 's labor force, and $a_{j}$ its productivity. From the previous assumptions, firm $j$ 's ex-post profits are given by:

$$
\begin{gathered}
\pi_{j}\left(q_{j}(\theta) \mid \theta\right)=q_{j}(\theta)\left(\theta-Q+v_{j}\right)-w_{j} N_{j} \\
=q_{j}(\theta)\left(\theta-Q-\bar{w}_{j}\right), j=1,2
\end{gathered}
$$

where $w_{j}$ is firm $j$ 's wage, $\bar{w}_{j}=\left(w_{j} / a_{j}\right)-v_{j}$, and $q_{j}(\theta)$ is firm $j$ 's output in state $\theta$. Ex-ante expected profits $\Pi_{j}$ are then equal to $E_{\theta}\left(\pi_{j}\left(q_{j}(\theta) \mid \theta\right)\right)$ (where $E_{\theta}$ denotes the expectations operator with respect to $\theta$ ). We assume that the firm $j$ 's manager payoff function coincides with firm $j$ 's profits (so that in this model there is no separation between ownership and control).

-Union objectives: We assume that layoffs take place by random assignment and that each firm's union maximizes the expected income of every member. ${ }^{7}$ The objective function of the union associated with the $j$-th firm is then given by:

$$
U_{j}=s_{j} w_{j}+\left(1-s_{j}\right) w^{a}, j=1,2
$$

where $s_{j}$ is the probability of staying employed at the same firm in the following period (the survival probability), and $w^{a}$ the expected income of a worker who loses his job. More precisely, $w^{a}=\varphi b+(1-\varphi) w^{e}$, where $\varphi$ is the probability of being unemployed, $b$ the unemployment benefit, and 
$w^{e}$ the competitive wage. ${ }^{8,9}$ We denote union $j$ 's membership by $M_{j}$, also referred to below as the insiders. Thus the survival probability of a union member, $s_{j} \in[0,1]$, is given by:

$$
s_{j}=\operatorname{Pr}\left\{N_{j}(\theta)>M_{j}\right\}+\operatorname{Pr}\left\{N_{j}(\theta) \leq M_{j}\right\}\left(E_{\theta}\left(N_{j}(\theta) \mid N_{j}(\theta) \leq M_{j}\right)\right) / M_{j}
$$

for $j=1,2$ and where $N_{j}(\theta)=q_{j}(\theta) / a_{j}$.

-Wage bargaining: The manager and the union associated with firm $j$ choose a wage $w_{j}$ to maximize firm $j$ 's joint surplus:

$$
\operatorname{Max}_{w ;} \Omega_{j}\left(w_{1}, w_{2}\right)=\mathrm{II}_{j}+\beta_{j} U_{j}
$$

subject to $(i) \pi_{j}\left(q_{j}(\theta) \mid \theta\right) \geq 0$ for all $\theta$, and $(i i) w_{j} \geq w^{\alpha}$.

where $\beta_{j}$ denotes firm $j$ 's union bargaining power. ${ }^{10}$ Restriction (i) ensures that both managers and workers are willing to preserve firm $j$ as an ongoing concern in any possible state of nature: bankruptcy costs are assumed to be so large that a manager would close down his firm rather than face negative profits in any possible state of nature. Since in equilibrium profit margins cannot be negative, restriction (i) in (4) can be rewritten as $q_{j}(\theta) \geq 0$ for all $\theta$. That is, restriction (i) implies that for all demand states, both firms are active in the product market. ${ }^{11}$ Restriction (ii) states that no worker would accept a job offer paying less than $w^{a}$.

A subgame perfect equilibrium (SPE) for our (two-stage) game is, therefore, an array $\left\{\left(w_{1}^{*}, w_{2}^{*}\right) ;\left(q_{1}^{*}\left(w_{1}, w_{2} ; \theta\right), q_{2}^{*}\left(w_{1}, w_{2} ; \theta\right)\right)\right\}$, where $\left(w_{1}^{*}, w_{2}^{*}\right)$ is the vector of equilibrium wages and $q_{j}^{*}\left(w_{1}, w_{2} ; \theta\right)$ is firm $j$ 's equilibrium output, such that:

(i) for any given $\theta$ and $\left(w_{1}, w_{2}\right),\left\{\left(q_{1}^{*}\left(w_{1}, w_{2} ; \theta\right), q_{2}^{*}\left(w_{1}, w_{2} ; \theta\right)\right)\right\}$ is a CournotNash equilibrium for the product market subgame, i.e., $q_{j}^{*}(\cdot) \in \arg \max \pi_{j}\left(q_{j}(\theta) \mid\right.$ 
$\theta)$ for all $j$, and

(ii) for all $j, w_{j}^{*} \in \arg \max \left\{\Omega_{j}\left(w_{1}, w_{2}\right) \mid q_{j}^{*}\left(w_{1}, w_{2} ; \theta\right) \geq 0\right.$ for all $\theta$, and $\left.w_{j} \geq w^{a}\right\} .12$

In order to ensure perfection we now proceed to solve the model by backward induction.

\subsection{PRODUCT MARKET COMPETITION}

In the second stage of the game, given wages and the realization of $\theta$, managers set production (employment) levels to maximize ex-post profits. It is a standard result that, for those parameter configurations such that both firms are active in the product market irrespective of the actual state of nature, there is a unique Cournot-Nash equilibrium for the product market subgame where

$$
\begin{gathered}
q_{j}^{*}\left(w_{1}, w_{2} ; \theta\right)=\left(\theta-2 \bar{w}_{j}+\bar{w}_{i}\right) / 3 \\
N_{j}^{*}(\theta)=q_{j}^{*}\left(w_{1}, w_{2} ; \theta\right) / a_{j} \\
\pi_{j}\left(q_{j}^{*}\left(w_{1}, w_{2} ; \theta\right) \mid \theta\right)=\left(q_{j}^{*}\left(w_{1}, w_{2} ; \theta\right)\right)^{2}
\end{gathered}
$$

for all $\theta \in[\underline{\theta}, \bar{\theta}]$. From the expression of $q_{j}^{*}\left(w_{1}, w_{2} ; \theta\right)$ in (5), it is immediate that those parameter configurations for which $q_{j}^{*}\left(w_{1}, w_{2} ; \underline{\theta}\right) \geq 0$ ensure that restriction (i) in (4) holds. This latter condition will be used below to set bounds on the feasible set of optimal wages at the bargaining stage.

Furthermore, from equation (5) it is easy to check that firm $j$ 's output, employment and profits are increasing in $\theta$ (the state of demand), $w_{i}$ (the competitor's wage), $a_{j}$ (firm $j$ 's productivity), and $v_{j}$ (consumers' willingness to pay for firm $j$ 's product); and decreasing in $a_{i}$ (competitor's productivity), 
and $v_{i}$ (consumers' willingness to pay for the competitor's product). In addition, $\pi_{j}\left(q_{j}^{*}\left(w_{1}, w_{2} ; \theta\right) \mid \theta\right)$ is decreasing and convex in $w_{j}$ (for all $\theta$ and $j$ ), and so is $\Pi_{j}=E_{\theta}\left[\left(q_{j}^{*}\left(w_{1}, w_{2} ; \theta\right)\right)^{2}\right]$. Hence, were wages decided by managers in isolation, they would be equal to $w^{a}$, the alternative income. ${ }^{13}$ Furthermore, using (5) it is easy to check that

$$
\frac{\partial^{2} \Pi_{j}}{\partial w_{j} \partial w_{i}} \leq 0 \text { for all } i, j
$$

so that, from the managers' point of view, wages are strategic substitutes: an increase in the rival's wage raises the marginal desirability of a wage cut for the frm's manager. The reason is that, as the rival increases his wage, it becomes easier to steal his business, which in addition becomes more valuable, as the price-cost margin also increases. ${ }^{14}$

\subsection{UNIONS' INCENTIVES}

We concluded the previous subsection by studying the managers' incentives to set wages. Now, before discussing the bargaining equilibrium outcome, we shall overview the corresponding unions' incentives.

First, notice that the survival probability $s_{j}$ given in equation (3) can also be written as

$$
s_{j}=\left\{\begin{array}{cc}
1 & \text { if } \theta_{j}^{*} \leq \underline{\theta} \\
\left(\bar{\theta}-\theta_{j}^{*}\right) / \Delta+\int_{\underline{\theta}}^{\theta_{j}^{*}}\left(N_{j}^{*}(\theta) / M_{j} \Delta\right) d \theta & \text { if } \underline{\theta}<\theta_{j}^{*} \leq \bar{\theta} \\
\int_{\underline{\theta}}^{\bar{\theta}}\left(N_{j}^{*}(\theta) / M_{j} \Delta\right) d \theta & \text { if } \bar{\theta}<\theta_{j}^{*}
\end{array}\right.
$$

where $\Delta=(\bar{\theta}-\underline{\theta})$ and $\theta_{j}^{*}$ is such that $N_{j}^{*}\left(\theta_{j}^{*}\right)=M_{j}{ }^{15}$ That is, for all $\theta \geq$ $\theta_{j}^{*}$, frm $j$ 's insiders are fully employed. Otherwise, some of them are laid 
off. Except for the first region in (7), where full employment implies that all derivatives of $s_{j}$ are zero, substitution of $N_{j}^{*}(\theta)$ from (5) into (7) yields that $s_{j}$ is unambigiously decreasing in $w_{j}$. That is, the probability of being laid off increases with higher wages, because a higher wage places the firm at a worse competitive position in the product market, leading to market share loses and employment cuts. Moreover, it is easily shown (see Result 1 in Appendix 1) that $s_{j}$ is increasing in $w_{i}$ and concave in $w_{j}$, and also that the second cross-derivative of $s_{j}$ with respect to $w_{j}$ and $w_{i}$ is positive. The latter two results do not hold for the third region in (7), where $M_{j}$ is large, since $s_{j}$ is linear in wages there. As will be seen below, in this third region -which is the only one considered in Davidson (1988), Dowrick (1989) and most of the related literature-, wages are necessarily strategic complements, but this need not be the case in the second and third regions. As a result, our model encompasses previous results regarding strategic complementarity and also opens the possibility of finding strategic substitutability.

Taking equations (2), (5) and (7) together we have that $U_{j}$ is (weakly) concave in $w_{j}$, and that it is increasing in $w_{j}$ if $s_{j}$ is larger, in absolute value, than $\left(\partial s_{j} / \partial w_{j}\right)\left(w_{j}-w^{a}\right)$. This is always true in the first region of $(7)$, since the latter product is zero, while in the other two regions, the sign of $\partial U_{j} / \partial w_{j}$ is ambiguous. Concerning the strategic nature of wages, they are strategic complements from the point of view of unions. In fact,

$$
\frac{\partial^{2} U_{j}}{\partial w_{j} \partial w_{i}}=\frac{\partial s_{j}}{\partial w_{i}}+\left(w_{j}-w^{a}\right) \frac{\partial^{2} s_{j}}{\partial w_{j} \partial w_{i}} \geq 0
$$

The intuition is as follows: as $w_{i}$ increases, firm $j$ 's competitive standing 
in the product market is improved, raising both its production and employment, which in turn increases $s_{j}\left(i . e ., \partial s_{j} / \partial w_{i} \geq 0\right.$ ). Moreover, the negative impact of a wage increase on the survival probability is also tempered as $w_{i}$ rises (that is, $\partial^{2} s_{j} / \partial w_{j} \partial w_{i} \geq 0$ ). To summarize, when $w_{i}$ rises, the union associated to firm $j$ can press further for an increase in $w_{j}$ without fearing layoffs so much. Therefore, workers' observed behavior of claiming wage increases to match their fellow workers' wages in competing firms is here shown to be a fully rational decision. While not denying their relevance, we do not need to refer to any psychological or sociological arguments, like felt fair pay or the equity theory (as it has been standard in the bargaining literature see, for instance, Martin (1992)-), to explain this pattern of behavior.

Note that standard models of monopolistic competition $\dot{a}$ la Dixit-Stiglitz and wage bargaining fail to capture the strategic effects described above. These models assume away any strategic interaction (i.e., $\partial^{2} U_{j} / \partial w_{j} \partial w_{i}=$ $\partial^{2} \Pi_{j} / \partial w_{j} \partial w_{i}=0$, for all $\left.i \neq j, i, j=1,2\right)$, by considering that the wage in one firm has a negligible impact on the demand for the goods produced by other firms. This strong assumption would be valid within our framework only if the product market was atomistic, and, in general, it has important implications for the understanding of the determinants of equilibrium wages and employment (see sections 3 and 4).

\subsection{EQUILIBRIUM WAGES}

In response to an increase in the wage at the competitor firm, managers' and unions' wage-setting incentives are thus in clear contradiction. Managers try 
to cut wages further in order to improve firms' operating margins and win additional market share. Unions, on the other hand, pursue to raise the earnings of their constituencies taking into account, however, the effect of their wage claims on employment. That is, the strategic nature of a wagesetting game between managers differs from the strategic nature of the same game if played between unions. Wages are strategic substitutes for the former game while they are strategic complements for the latter.

This confrontation between unions and managers at the firm level is resolved through the bargaining process. In order to characterize its solution, it is useful to notice that the objective function $\Omega_{j}$ is, in general, not quasiconcave in $w_{j}$, since $\Pi_{j}$ is convex and $U_{j}$ is concave. So, we cannot ensure either existence or uniqueness of a pure-strategy equilibrium for all admissible parameter values. As is well known, the lack of quasi-concavity of the objective functions generates discontinuities in the best-reply functions, which may lead to either non-existence or multiplicity of equilibria. Hence, in this section we prove existence by construction. Also note that restrictions (i) and (ii) in equation (4) imply that $w_{j}$ must be within the range $\left[w^{a}, w_{j}^{+}\right]$, where $w_{j}^{+}=a_{j}\left(\underline{\theta}+v_{j}\right){ }^{16}$

In view of this feasible wage set, the value of $w_{j}$ which maximizes $\Omega_{j}$ for a given $w_{i}$ (i.e., firm $j$ 's best reply) may be a corner or an interior solution. For example, if $\beta_{j}$ is low enough, then the shape of $\Omega_{j}$ is dominated by the properties of the profit function $\Pi_{j}$, which is decreasing and convex for all feasible wages, so that firm $j$ 's best reply is $w^{a}$. Similarly, there exist parameter configurations for which $w_{j}^{+}$is firm $j$ 's best reply. Leaving aside the pure corner solutions, the typical shape of $\Omega_{j}$ as a function of $w_{j}$ is given 
in Figure 1. It arises from two facts: first, for the functional forms chosen for $\Pi_{j}$ and $U_{j}$ in this paper, $\Omega_{j}$ is cubic in $w_{j}$ (i.e., there is at most one interior maximum); second, the convex part of the function always precedes the concave part (this is proved in Result 2 in Appendix 1). Hence, in this case there will always exist an interior maximum where $\Omega_{j}$ is locally concave. This may be a global maximum (solid line in Figure 1) and, thus, firm $j$ 's best reply, or it may be just a local one (dashed line), so that $w^{a}$ is the best reply. Therefore, if $w_{j} \in\left(w^{a}, w_{j}^{+}\right)$is the best reply of firm $j$ given $w_{i}$, the function $\Omega_{j}$ must be locally concave in a neighborhood of $w_{j}$ and the condition $\Omega_{j}\left(w_{i}, w_{j}\right) \geq \Omega_{j}\left(w_{i}, w^{a}\right)$ must hold. From now on we concentrate on this last case.

In an interior equilibrium, wages jointly solve the following first-order conditions:

$$
\partial \Omega_{j} / \partial w_{j}=\partial \Pi_{j} / \partial w_{j}+\beta_{j} \partial U_{j} / \partial w_{j}=0, j=1,2 .
$$

From this equation, and since $\partial \Pi_{j} / \partial w_{j}<0$ for all $w_{j}$, we have that, at any interior equilibrium, $\partial U_{j} / \partial w_{j}$ must be positive. This implies that equilibrium wages are too low from the point of view of unions and too high from the perspective of managers. A direct implication is that, ceteris paribus, union activity (represented by $\beta_{j}>0$ for all $j$ ) lowers firms' profitability, in accordance with the existing evidence. ${ }^{17}$

Furthermore, in accordance with the arguments above, a pair $\left(w_{1}^{*}, w_{2}^{*}\right)$ solving the first-order conditions in (9) constitutes a proper interior equilibrium if no deviation is privately optimal. Necessary and sufficient conditions for this are: (i) $\beta_{j} \geq \bar{\beta}_{j}\left(w_{1}^{*}, w_{2}^{*}\right)=-\left(\partial^{2} \Pi_{j} / \partial w_{j}^{2}\right) /\left(\partial^{2} U_{j} / \partial w_{j}^{2}\right)$, with 


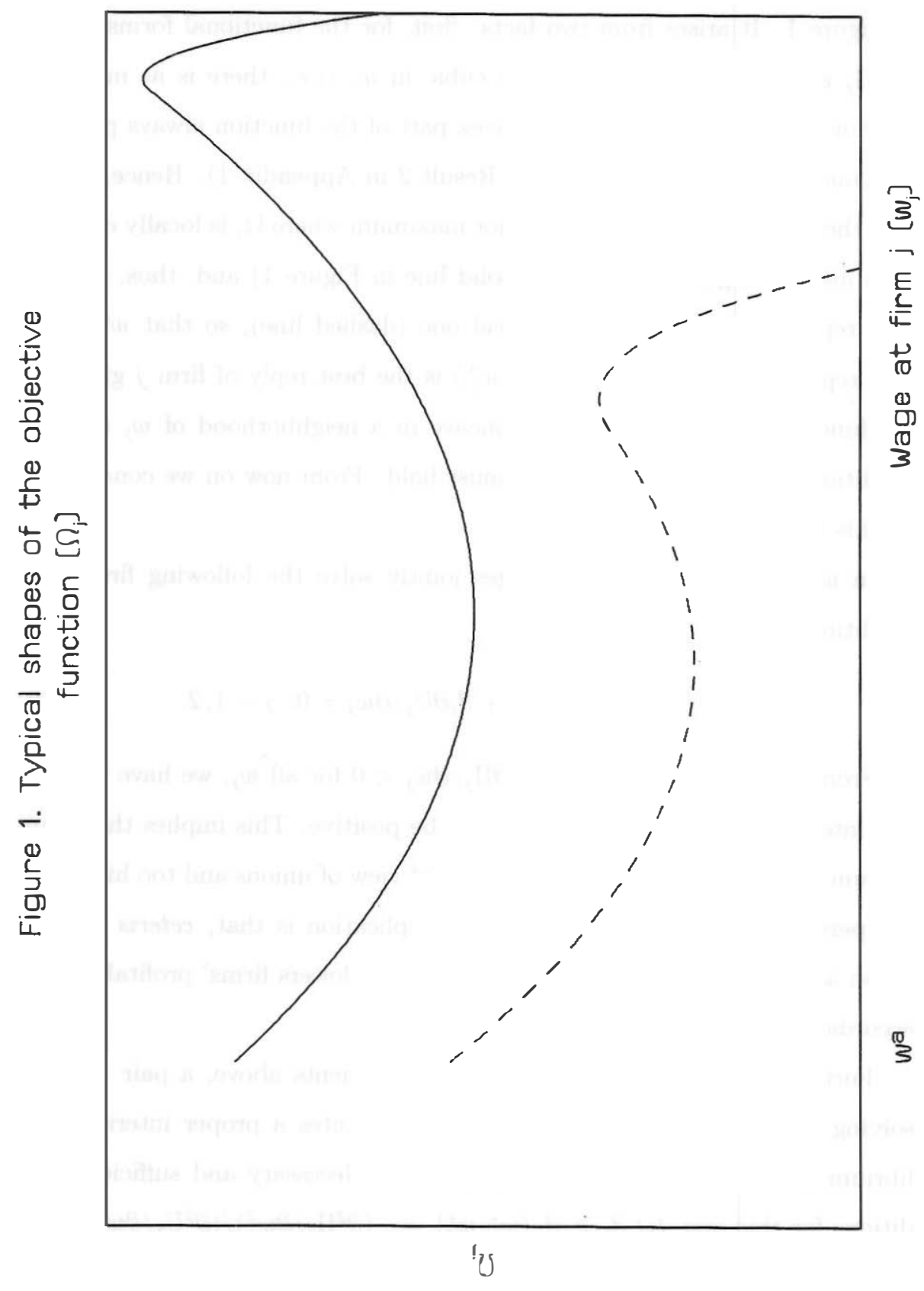

$-18-$ 
$\bar{\beta}_{j}\left(w_{1}^{*}, w_{2}^{*}\right) \in(0, \infty)$, for all $j$ (with the second-order derivatives evaluated at $\left.\left(w_{1}^{*}, w_{2}^{*}\right)\right)$, so that second-order conditions are satisfied locally; and (ii) $\Omega_{j}\left(u_{i}^{*}, w_{j}^{*}\right) \geq \Omega_{j}\left(w_{i}^{*}, w^{a}\right)$, for all $i, j=1,2 \cdot{ }^{18}$

The local strategic nature of the bargaining game at an interior equilibrium $\left(w_{1}^{*}, w_{2}^{*}\right)$ (i.e., the sign of $\left.\partial^{2} \Omega_{j} / \partial w_{j} \partial w_{i}\right)$ also depends on the exact magnitude of $\beta_{j}$. If $\beta_{j} \geq \beta_{j}^{*}\left(w_{1}^{*}, w_{2}^{*}\right)=-\left(\partial^{2} \Pi_{j} / \partial w_{j} \partial w_{i}\right) /\left(\partial^{2} U_{j} / \partial w_{j} \partial w_{i}\right)$, with $\beta_{j}^{*}\left(w_{1}^{*}, w_{2}^{*}\right) \in(0, \infty)$, for all $j$ (with the cross-derivatives evaluated at $\left.\left(w_{1}^{*}, w_{2}^{*}\right)\right)$, then $\partial^{2} \Omega_{j} / \partial w_{j} \partial w_{i} \geq 0$, and vice versa. That is, provided union bargaining power is sufficiently high, the bargaining game shows strategic complementarity among its decision variables. Otherwise, it is characterized by strategic substitutability. It can be also shown (see Result 3 in Appendix 1) that $\beta_{j}^{*}\left(w_{1}^{*}, w_{2}^{*}\right) \geq \bar{\beta}_{j}\left(w_{1}^{*}, w_{2}^{*}\right)$ for all $j$ and $\left(w_{1}^{*}, w_{2}^{*}\right)$, so that both the strategic substitutes and the strategic complements cases are relevant for our comparative statics analysis below. Figure 2 depicts the relevant ranges of $\beta_{j}$ defined by the cutoff points $\beta_{j}^{*}, \bar{\beta}_{j}$, and another cutoff point, $\widehat{\beta}_{j}$ (defined below), which ensures stability of the equilibrium.

We now present two examples of equilibria satisfying the conditions above. Figure 3 shows a symmetric example of a unique interior equilibrium with local strategic substitutability (i.e., downward-sloping best-reply functions) and Figure 4 shows one with local strategic complementarity (i.e., upwardsloping best-reply functions). (The lines appearing in the graphs represent the first-order conditions, but only their solid segments constitute proper best-reply functions.) All parameters are the same in both figures, except for $\beta$, which is higher in the second one. ${ }^{19}$ 
Figure 2. Characterization of interior equilibria with $\beta_{j}=\beta_{i}$

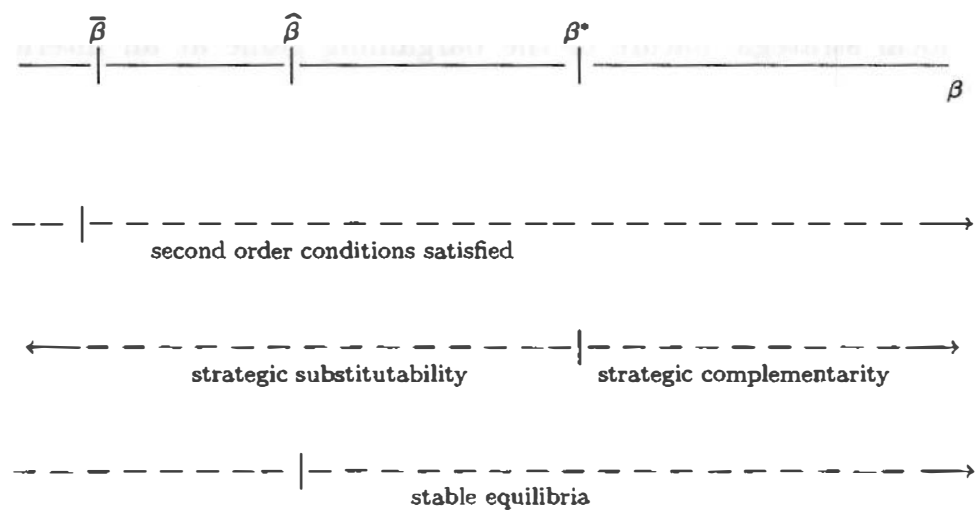




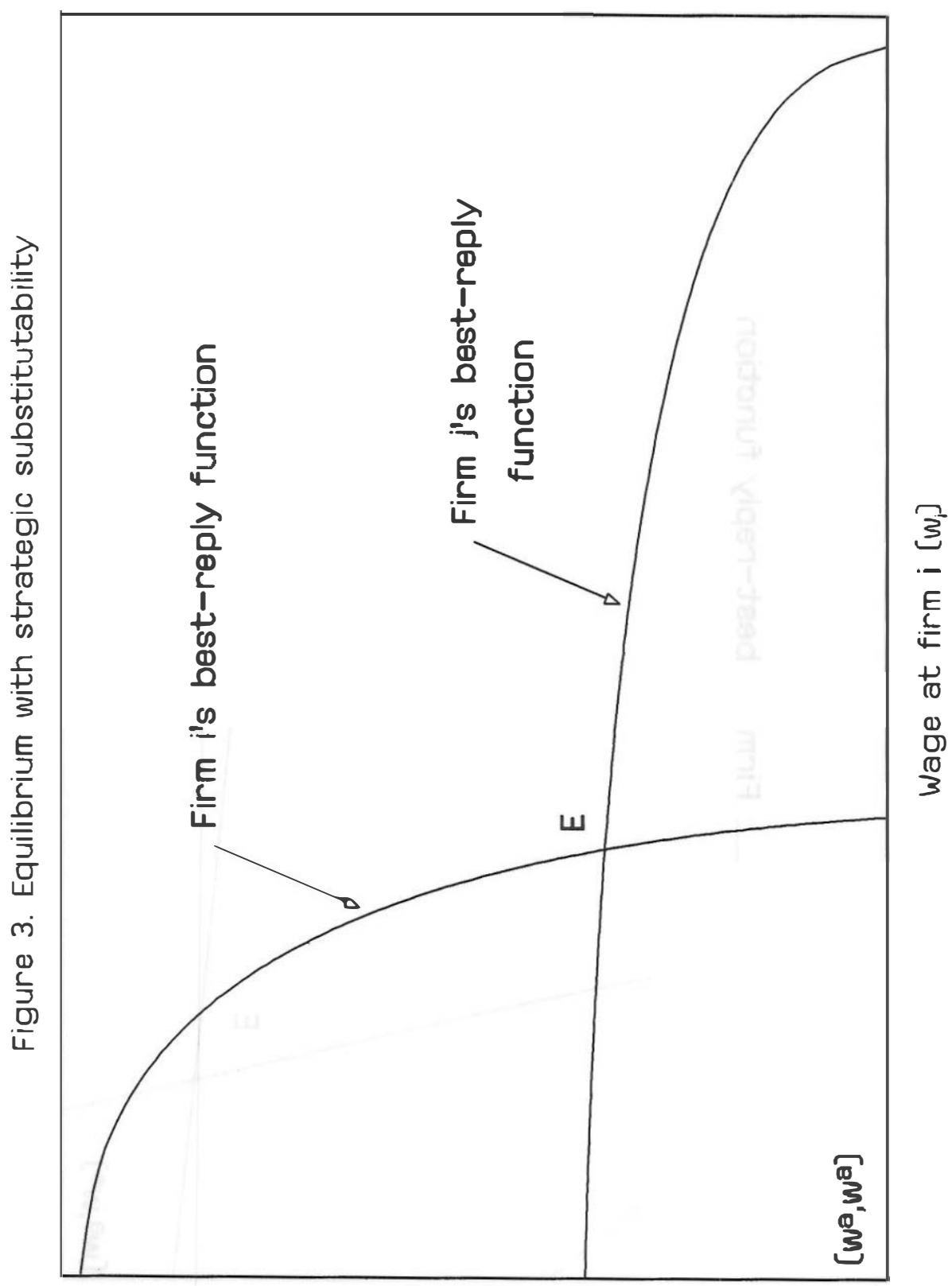

$[' m]$ ! سu! ze abem 


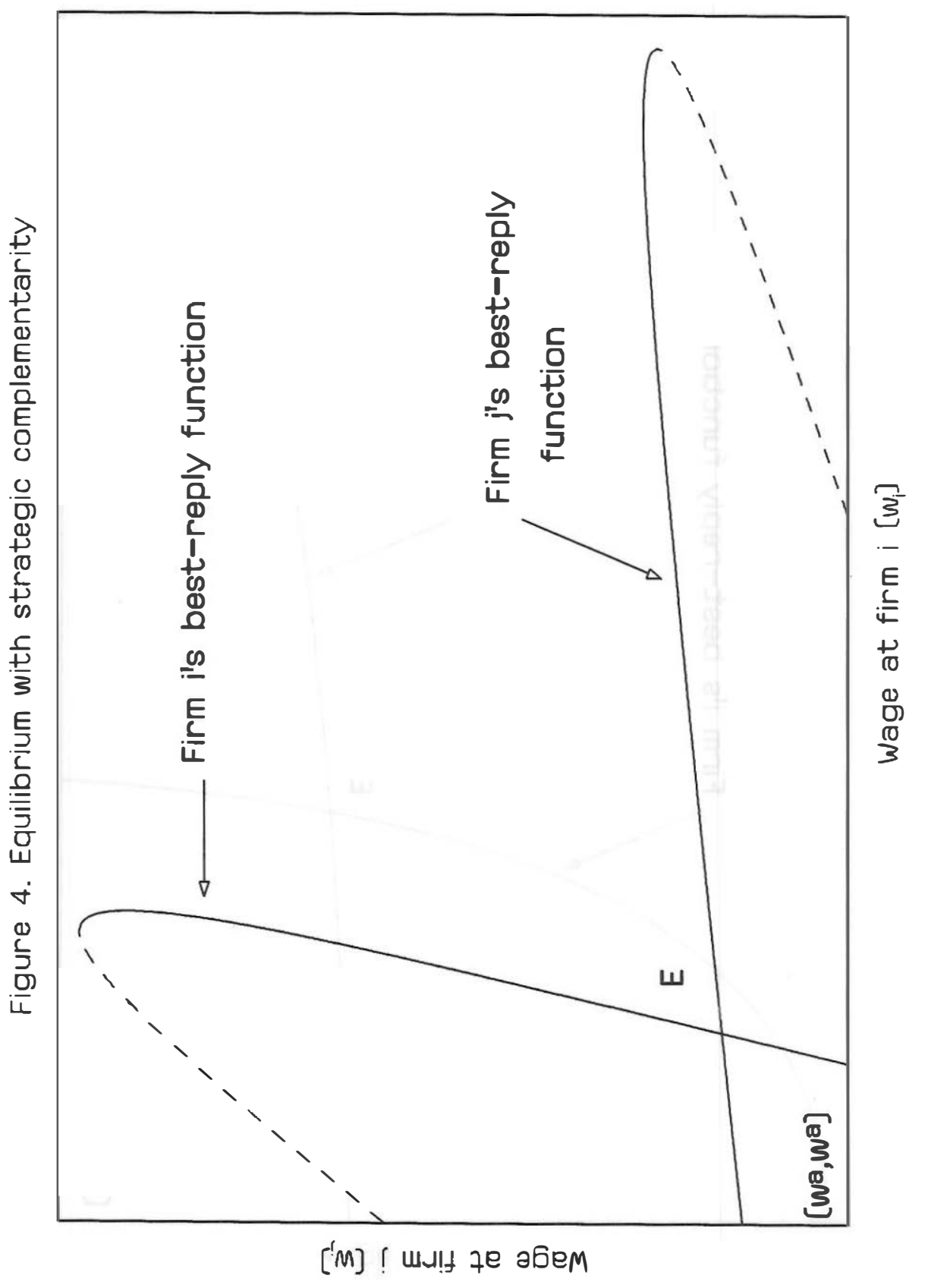


Had we restricted our analysis to those parameter sets for which $\theta_{j}^{*}>\bar{\theta}$ by assuming $M_{j}$ sufficiently large -as is typically done in the literature-, we would have concluded that there is no equilibrium featuring strategic substitutability (proof of this statement is given in Result 4 in Appendix 1).

To conclude this section, let us remark again that we cannot ensure the uniqueness of equilibrium, even if best-reply functions are single-valued. First, since the objective functions are not necessarily quasi-concave, the best-reply functions may be discontinuous, raising the possibility of multiple equilibria, as illustrated in Figure 5a. Second, the shape of the objective functions implies that the best-reply functions are in general non-linear, which again opens the door to multiplicity (as depicted in Figure 5b).

\section{COMPARATIVE STATICS}

The goal of this section is to analyze how equilibrium wages and employment rear:t to changes in their basic determinants. However, given the lack of global quasi-concavity, our comparative statics analysis is only valid locally. The parameters of interest for this analysis are: $w^{a}$ (the expected income of a worker who loses his job), $\beta_{1}$ and $\beta_{2}$ (the bargaining power of the unions associated to firms 1 and 2, respectively), $M_{1}$ and $M_{2}$ (firms' respective numbers of insiders), $a_{1}$ and $a_{2}$ (firms' labor productivity), and finally, $v_{1}$ and $v_{2}$ (the indices of brand and quality differentiation).

Let $\alpha=\left(w^{a}, \beta_{1}, \beta_{2}, M_{1}, M_{2}, a_{1}, a_{2}, v_{1}, v_{2}\right)$ be the vector of parameters of interest, and $\alpha_{k}$ its $k$-th element $(k=1, \ldots, 9)$. Then, by implicit differentia- 
Figure 5. Multiple equilibria

$5 a$.

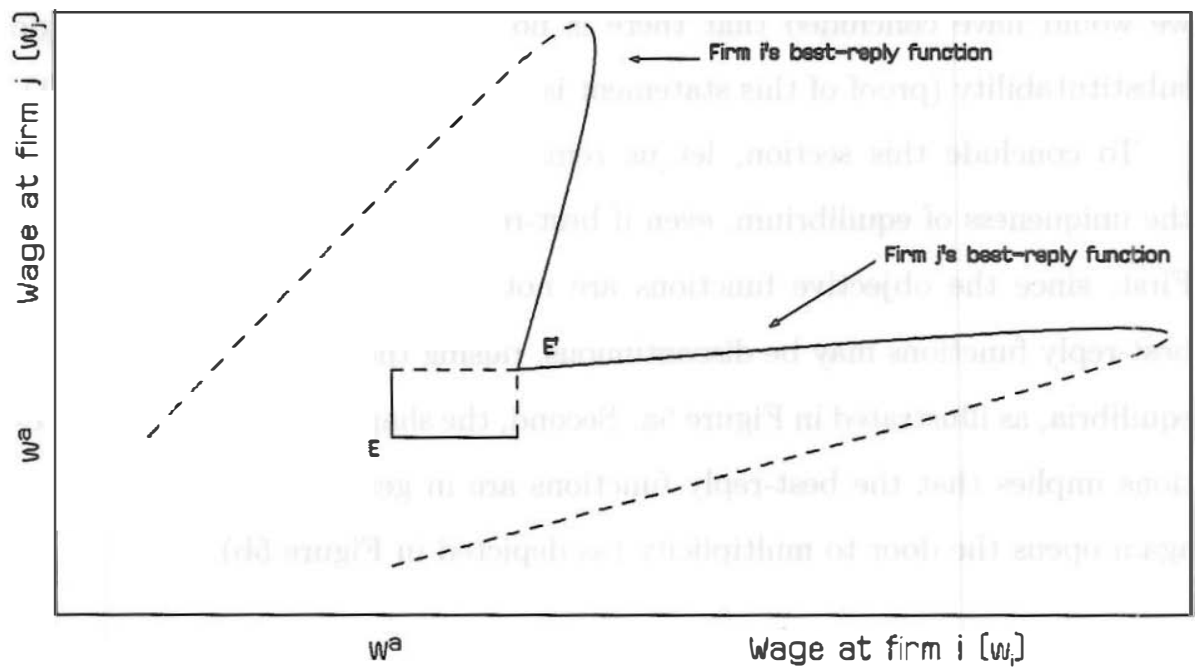

$5 b$.

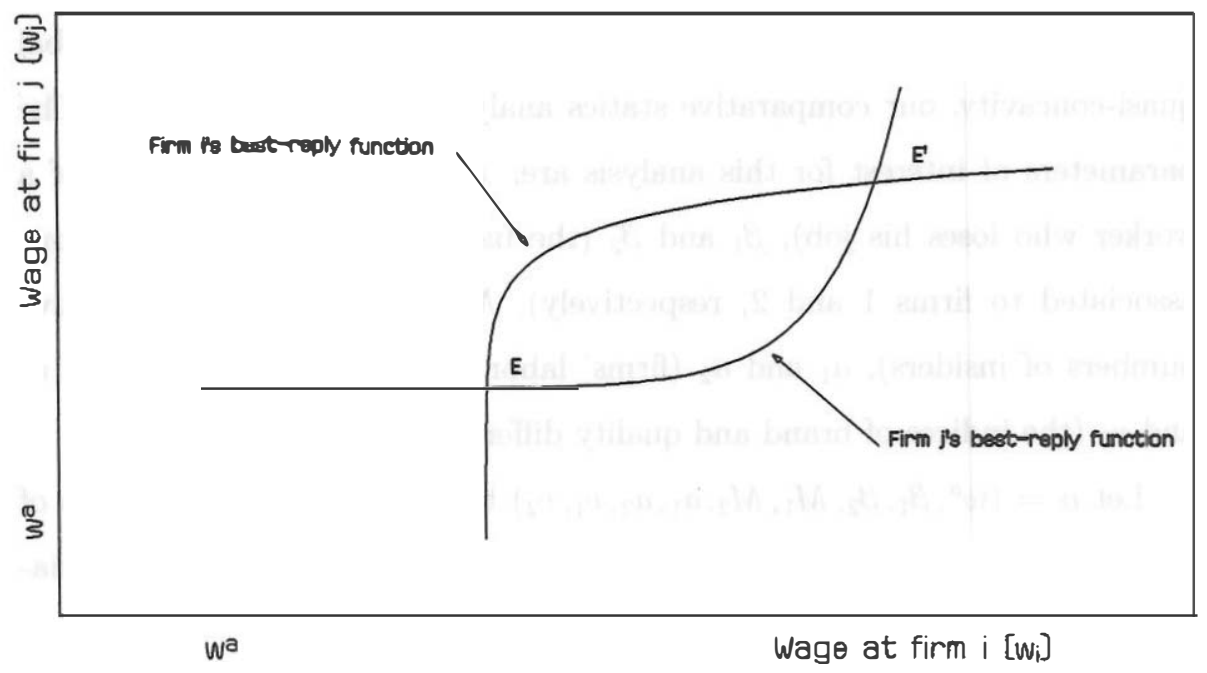


tion:

$$
\left(\begin{array}{c}
\partial w_{1}^{*} / \partial \alpha_{k} \\
\partial w_{2}^{*} / \partial \alpha_{k}
\end{array}\right)=-\left(\begin{array}{cc}
\partial^{2} \Omega_{1} / \partial w_{1}^{2} & \partial^{2} \Omega_{1} / \partial w_{1} \partial w_{2} \\
\partial^{2} \Omega_{2} / \partial w_{1} \partial w_{2} & \partial^{2} \Omega_{2} / \partial w_{2}^{2}
\end{array}\right)^{-1}\left(\begin{array}{c}
\partial^{2} \Omega_{1} / \partial w_{1} \partial \alpha_{k} \\
\partial^{2} \Omega_{2} / \partial w_{2} \partial \alpha_{k}
\end{array}\right)
$$

where all cross-derivatives in (10) are evaluated at equilibrium values. From (10) we have that for all $i \neq j$ and all $k$,

$$
\partial w_{j}^{*} / \partial \alpha_{k}=\eta_{j} / \gamma
$$

where

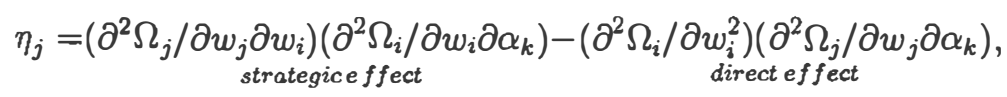

and

$$
\gamma=\left(\partial^{2} \Omega_{j} / \partial w_{j}^{2}\right)\left(\partial^{2} \Omega_{i} / \partial w_{i}^{2}\right)-\left(\partial^{2} \Omega_{j} / \partial w_{j} \partial w_{i}\right)\left(\partial^{2} \Omega_{i} / \partial w_{i} \partial w_{j}\right)
$$

Any sensible comparative statics exercise requires at least local stability. It can be easily shown that for any interior equilibrium $\left(w_{1}^{*}, w_{2}^{*}\right)$, there exists a critical value $\widehat{\beta}_{j}\left(w_{1}^{*}, w_{2}^{*}\right) \in\left(\bar{\beta}_{j}\left(w_{1}^{*}, w_{2}^{*}\right), \beta_{j}^{*}\left(w_{1}^{*}, w_{2}^{*}\right)\right)$, such that if $\beta_{j} \geq$ $\widehat{\beta}_{j}\left(w_{1}^{*}, w_{2}^{*}\right)$ the equilibrium is stable, implying that the denominator of (11) is positive. ${ }^{20}$ As a result, there may exist stable equilibria featuring either strategic substitutability or complementarity (see Figure 2). For example, the unique interior equilibria in Figures 3 and 4 are both stable.

Hence, under stability, the sign of $\partial w_{j}^{*} / \partial \alpha_{k}$ is equal to the sign of the numerator of (11), $\eta_{j}$. A change in the $k$-th parameter of interest, $\alpha_{k}$, has two kinds of effects on equilibrium wages: direct effects, captured by the second term in $\eta_{j}$, and strategic effects, represented by the first term in $\eta_{j}$. The 
direct effects lead to shifts of the firms' reaction functions, while the strategic effects lead to movements along the reaction functions. (Notice again that traditional monopolistic competition models omit these latter strategic effects by implicitly assuming that $\partial^{2} \Omega_{j} / \partial w_{j} \partial w_{i}=0$ for all $i \neq j$.)

From (10) and (11) it is clear that to derive our comparative statics exercises we need to go into the signs of the cross-derivatives $\partial^{2} \Omega_{j} / \partial w_{j} \partial \alpha_{k}$ and, therefore, into the signs of $\partial^{2} U_{j} / \partial w_{j} \partial \alpha_{k}$ and $\partial^{2} \Pi_{j} / \partial w_{j} \partial \alpha_{k}$, for all $j, k$. The latter expressions represent the change in the bargaining attitudes of unions and managers, respectively, when $\alpha_{k}$ rises. Table 1 summarizes these signs.

Most results in Table 1 are rather intuitive. For instance, an increase in $w^{a}$ (due to either an increase in the unemployment benefit, $b$, or in the competitive wage, $w^{e}$, or else to a fall in the probability of unemployment, $\varphi$ ) raises the union's marginal utility from a wage increase (i.e., $\partial^{2} U_{j} / \partial w_{j} \partial w^{a} \geq$ $0)$, as laid-off workers benefit from an increase in their expected income (decreasing the cost of becoming unemployed at the margin). Consequently, raising $w^{a}$ leads to a higher firm $j$ 's wage, $w_{j}$, for a given value of $w_{i}, i \neq j$. This is also the case when the number of firm $j$ 's insiders shrinks. A fall in $M_{j}$ raises the survival probability, $s_{j}$, for any employee of firm $j$ and for given wages and, more importantly, makes $s_{j}$ less sensitive to an increase in $w_{j}$. Therefore, the union is more likely to press further in order to raise the wage bill of its own firm, since layoffs become less of a threat for its membership.

Other results are, perhaps, less intuitive. For instance, an increase in firm j's productivity, $a_{j}$, has ambiguous effects. First, it affects the managers' incentives at the margin, but in an ambiguous fashion. On the one hand, 
TABLE 1

CROSS-DERIVATIVES OF $\Pi_{j}, U_{j}$, AND $\Omega_{j}$ WITH RESPECT TO $w_{j}$ AND THE MODEL'S PARAMETERS ${ }^{1}$

\begin{tabular}{|c|c|c|c|c|c|c|c|c|c|}
\hline & \multicolumn{5}{|c|}{$\alpha^{1}$} & \multicolumn{4}{|c|}{$\alpha^{2}$} \\
\hline & $w^{a}$ & $\beta_{j}$ & $M_{j}$ & $\beta_{i}$ & $M_{i}$ & $a_{j}$ & $a_{i}$ & $v_{j}$ & $v_{i}$ \\
\hline \multirow[t]{2}{*}{$\Pi_{j}$} & 0 & 0 & 0 & 0 & 0 & $?$ & $?$ & - & + \\
\hline & $(0)$ & $(0)$ & (0) & (0) & $(0)$ & (?) & (0) & $(-)$ & (0) \\
\hline \multirow[t]{2}{*}{$U_{j}$} & + & 0 & - & 0 & 0 & $?$ & - & + & - \\
\hline & $(+)$ & $(0)$ & $(-)$ & (0) & $(0)$ & (?) & (0) & $(+)$ & (0) \\
\hline \multirow[t]{2}{*}{$\Omega_{j}$} & + & + & - & 0 & 0 & $?$ & $?$ & $?$ & $?$ \\
\hline & $(+)$ & $(+)$ & $(-)$ & (0) & (0) & (?) & (0) & $(?)$ & (0) \\
\hline
\end{tabular}

${ }^{1}$ Signs in parentheses correspond to the same cross-derivatives for the monopolistic competition model. 
cutting wages becomes more att:active in this case since it is easier to steal the rival's market-share. However, as the firm becomes more productive, wage increases become relatively less costly. Second, it also changes the union's marginal utility from a wage increase. This latter effect does not have a clear sign either. The reason is that an increase in $a_{j}$ affects firm $j$ 's employment, and the survival probability, in two opposite ways. For a given level of output $q_{j}$ an increase in $a_{j}$ makes some workers redundant (thus reducing $s_{j}$ ) but, on the other hand, the higher $a_{j}$ the more competitive is firm $j$ in the product market, which raises $q_{j}^{*}, N_{j}^{*}$ and $s_{j}$. The first of these two effects on $a_{j}$ reduces the union's marginal utility from a wage increase, while the second effect tends to raise it.

If we analyze the effect on firm $j$ 's bargaining agents of an increase in firm $i$ 's productivity, the ambiguity still persists. Concerning the attitudes of firm $j$ 's manager, a rise in $a_{i}$ makes him more accommodating at the bargaining table since a greater wage reduction would be necessary to steal market share from firm $i$ (i.e., $\partial^{2} \Pi_{j} / \partial w_{j} \partial a_{i} \geq 0$ ). However, the union associated to firm $j$ restrains its wage claims at the same time, as $s_{j}$ becomes more sensitive to wage increases (i.e., $\left.\partial^{2} U_{j} / \partial w_{j} \partial a_{i} \leq 0\right)$.

As in the previous case, an increase in firm $i$ 's brand quality, $v_{i}$, makes firm $j$ 's manager less willing to undercut the rival's wages as its offer becomes relatively less valuable for consumers, and hence his ability to steal firm $i$ 's market share is reduced (that is, $\partial^{2} \Pi_{j} / \partial w_{j} \partial v_{i} \geq 0$ ). However, it also reduces the union's incentives to press for wage increases $\left(\partial^{2} U_{j} / \partial w_{j} \partial v_{i} \leq 0\right)$ since it raises the sensitivity of $s_{j}$ to $w_{j}$. Exactly the opposite holds when we consider the impact of an increase in $v_{j}$ on the firm $j$ 's manager and union. 
We can thus distinguish between two types of parameters. The parameters in $\alpha^{1}=\left(w^{a}, \beta_{1}, \beta_{2}, M_{1}, M_{2}\right)$ are those for which the sign of $\partial^{2} \Omega_{j} / \partial w_{j} \partial \alpha_{k}$ is unambiguous, whilst for those in $\alpha^{2}=\left(a_{1}, a_{2}, v_{1}, v_{2}\right)$ this sign depends on the exact value of $\beta_{j}$. The next subsection studies analytically the comparative statics of equilibrium wages with respect to the parameters in $\alpha^{1}$. Section 3.2 deals with the corresponding results for the parameters in $\alpha^{2}$, by means of numerical simulations.

\subsection{ANALYTICAL RESULTS}

From equation (11) and the results in Table 1, Propositions 1 and 2 below follow immediately. (Table 2 surnmarizes them.)

Proposition 1 At any interior equilibrium $\left(w_{1}^{*}, w_{2}^{*}\right)$ featuring strategic complementarity, firm $j$ 's equilibrium wage (employment) is locally increasing (decreasing) in $w^{a}, \beta_{j}$, and $\beta_{i}$, and locally decreasing (increasing) in $M_{j}$ and $M_{i}, i \neq j, i, j=1,2$.

Proposition 1 characterizes the bargaining outcome when wages are local strategic complements. In this case, firms $j$ 's equilibrium wage, $w_{j}^{*}$, is shown to rise with $w^{a}$ and $\beta_{j}$, and to fall with $M_{j}$, as the standard monopolistic competition model would predict (see Layard et al. (1991)). But $w_{j}^{*}$ can also be shown to rise with the rival's union power, $\beta_{i}$, and to fall with the rival's number of insiders, $M_{i}$. The last two effects are exclusively strategic so that they cannot be captured by a model such as the monopolistic competition model, which disregards strategic interactions among competing firms. Fur- 
TABLE 2

EFFECTS OF UNAMBIGUOUSLY-SIGNED PARAMETERS ON EQUILIBRIUM WAGES $\left(\partial w_{j} / \partial \alpha_{k}^{1}\right)$

\begin{tabular}{lcccccc} 
Model & $w^{\alpha}$ & $\beta_{j}$ & $M_{j}$ & $\beta_{i}$ & $M_{i}$ \\
\hline Symmetric models $^{1}$ & + & + & - & 0 & 0 \\
This model: & & & & & & \\
- Strategic complements $\left(\beta_{j} \geq \beta_{j}^{*}\right)$ & + & + & - & + & - \\
- Strategic substitutes $\left(\beta_{j}<\beta_{j}^{*}\right)$ & $?$ & + & - & - & + \\
\hline
\end{tabular}

1 This includes both non-strategic models, like the model of monopolistic competition (e.g. Blanchard and Kiyotaki (1987) or Layard et al. (1991)), and strategic oligopoly models imposing symmetry across firms (e.g. Davidson (1988) or Dowrick (1989)). 
thermore, these results do not appear in Davidson (1988) or Dowrick (1989) because of their symmetry assumption by which $\beta_{j}=\beta$ for all $j$.

Consider, for example, an increase in $\beta_{i}$. This has a direct and positive effect on $w_{i}$ for any given $w_{j}$ (i.e., $\partial^{2} \Omega_{i} / \partial w_{i} \partial \beta_{i} \geq 0$ ). Firm $j$ 's reaction function remains unchanged, instead, since $\partial^{2} \Omega_{j} / \partial w_{j} \partial \beta_{i}=0$. However, the initial increase in $w_{i}$ due to a greater $\beta_{i}$, leads to a subsequent increase in $w_{j}$, as wages are strategic complements. The final impact of an increase in $\beta_{i}$ is, therefore, to raise both equilibrium wages $w_{i}^{*}$ and $w_{j}^{*}$. Notice that the impact of $\beta_{i}$ on $w_{j}^{*}$ is purely strategic.

Moreover, the impact on $w_{j}^{*}$ of changes in $w^{a}, \beta_{j}$, and $M_{j}$, although qualitatively identical in the monopolistic competition and the oligopolistic models, may be quantitatively very different. For instance, consider the effect of an increase in $w^{a}$ : it raises $\partial \Omega_{j} / \partial w_{j}$ making it more profitable for firm $j$ to raise wages, but it also raises $\partial \Omega_{i} / \partial w_{i}$ and thus $w_{i}^{*}$. Since wages are strategic complements, firm $j$ would react to an increase in $w_{i}$ by increasing its own wage. This is precisely the strategic effect missing in models of monopolistic competition, which biases $\partial w_{j}^{*} / \partial w^{a}$ downwards in this latter kind of models.

Proposition 2 At any interior equilibrium $\left(w_{1}^{*}, w_{2}^{*}\right)$ featuring strategic substitutability, firm $j$ 's equilibrium wage (employment) is locally increasing (decreasing) in $\beta_{j}$ and $M_{i}$, but locally decreasing (increasing) in $M_{j}$ and $\beta_{i}$, $i \neq j, i, j=1,2$.

Proposition 2 focuses on the case where wages are strategic substitutes. Our basic comparative statics results are substantially modified with respect to the strategic complements case in Proposition 1. The equilibrium wage, 
$w_{j}^{*}$, still rises as firm $j$ 's union becomes more powerful in the bargaining process (as $\beta_{j}$ rises) or as $M_{j}$ shrinks, but it now falls with $\beta_{i}$, firm $i$ 's union power. This is because as $\beta_{i}$ rises firm $i$ 's wage also rises, which makes it more profitable for firm $j$ to cut its wages in order to win a greater share of the market. Since for these values of the $\beta$ 's the bargaining outcome is dictated by managers incentives, $w_{j}^{*}$ must fall. A similar intuition also applies for reductions in $M_{i}$. Also in contrast with the strategic complements case, the effect on equilibrium wages of an increase in $w^{a}$ is, in principle, ambiguous. Of course, raising $w^{a}$ has a positive direct effect on firms' wages since it strengthens the bargaining positions of unions by reducing each member's marginal loss from a lay-off. However, given strategic substitutability, as the rival's wage increases, it is more profitable to cut one's wage, which pushes equilibrium wages in the opposite direction. Remarkably, this case has been ignored, not only in the literature on monopolistic competition, but also in the existing oligopolistic modelssuch as Davidson (1988) and Dowrick (1989).

\subsection{NUMERICAL COMPUTATIONS}

As regards the comparative statics results concerning the variables contained in vector $\alpha^{2}$, we have to resort to numerical computations in order to sign those effects. We have found that the results lack robustness with respect to the various parameter configurations which yield equilibria as well as to the values of $\beta$. This outcome challenges comparative statics results arising from models which ignore strategic interactions.

Take, for instance, the effect of productivity changes on wages. In pre- 


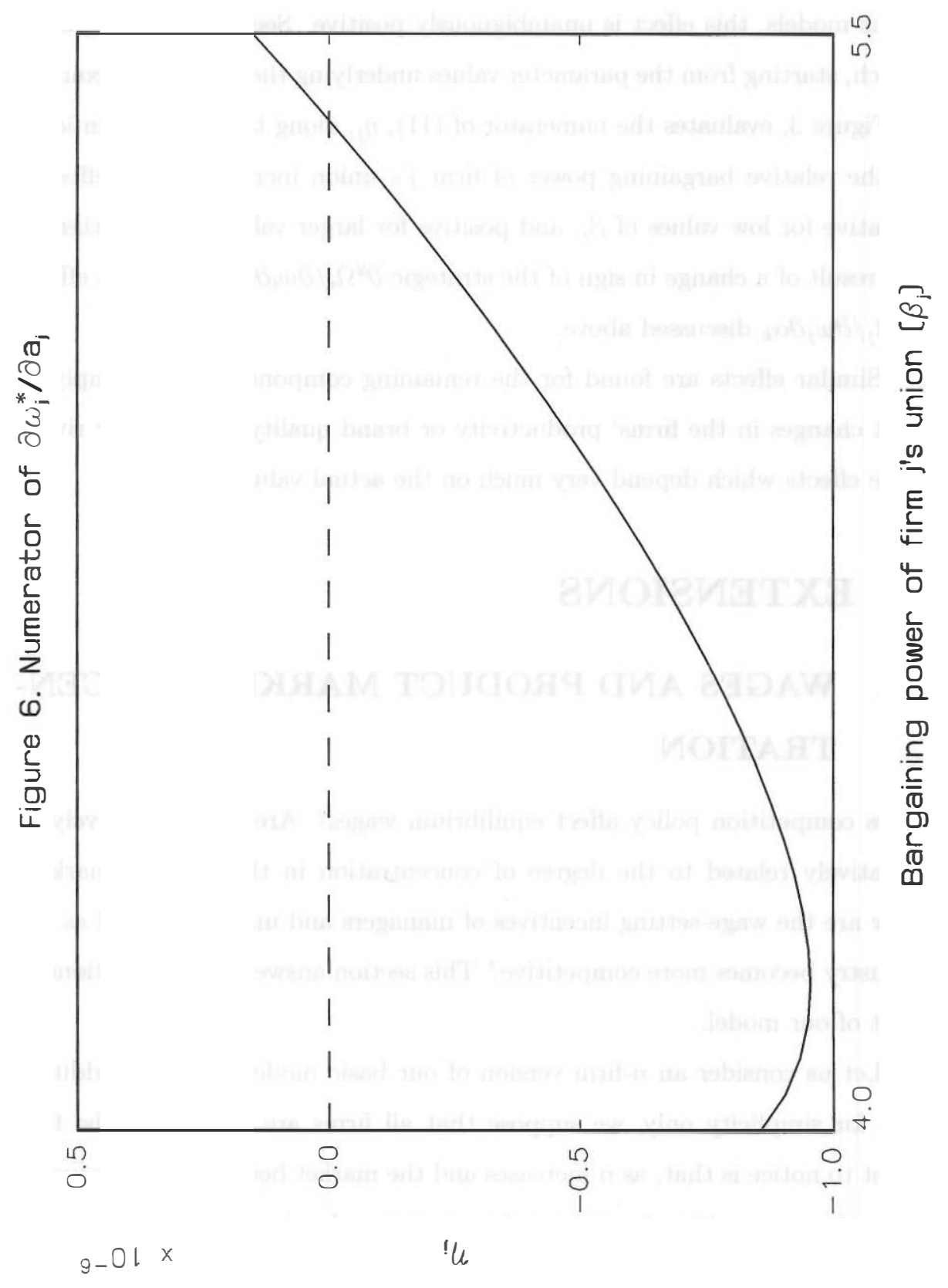


vious models, this effect is unambiguously positive. See, however, Figure 6, which, starting from the parameter values underlying the symmetric example in Figure 3, evaluates the numerator of $(11), \eta_{j}$, along the equilibrium locus as the relative bargaining power of firm $j$ 's union increases. The effect is negative for low values of $\beta_{j}$, and positive for larger values. This pattern is the result of a change in sign of the strategic $\partial^{2} \Omega_{i} / \partial w_{i} \partial \alpha_{k}$ and direct effects $\partial^{2} \Omega_{j} / \partial w_{j} \partial \alpha_{k}$ discussed above.

Similar effects are found for the remaining components of $\alpha^{2}$, implying that changes in the firms' productivity or brand quality and in their rivals' have effects which depend very much on the actual value of $\beta$.

\section{EXTENSIONS}

\subsection{WAGES AND PRODUCT MARKET CONCEN- TRATION}

Does competition policy affect equilibrium wages? Are wages positively or negatively related to the degree of concentration in the product market? How are the wage-setting incentives of managers and unions changed as the industry becomes more competitive? This section answers these questions in light of our model.

Let us consider an $n$-finm version of our basic model where, in addition and for simplicity only, we suppose that all firms are identical. The first point to notice is that, as $n$ increases and the market becomes more competitive, the wage-setting incentives of managers and unions change in opposite 
dires:tions. While managers become less eager to undercut rivals' wages (i.e., $\partial^{2} \Pi_{j} / \partial w_{j} \partial n \geq 0$ ) and, therefore, more accommodating in the bargaining table, unions exert less pressure to raise wages (i.e., $\partial^{2} U_{j} / \partial w_{j} \partial n \leq 0$ ). Thus, from the viewpoint of the former, wage reductions are relatively less profitable when the industry works with very small price-cost margins, that is, when the market is very competitive. ${ }^{21}$ For unions, on the contrary, as $n$ rises a wage increase becomes less valuable since it is less likely that member workers could enjoy the higher wage, as the survival probability of any insider falls with $n$. Furthermore, the fall in the survival probability is larger for higher wages.

Therefore, the overall relationship between equilibrium wages and market concentration is, in principle, ambiguous. Our main interest is, however, in understanding the behavior of wages when unions do matter. Hence, suppose that union's bargaining power is such that (i) $\partial^{2} \Omega_{j} / \partial w_{j} \partial w_{i} \geq 0$ for all $i \neq j$, $i, j=1, \ldots, n$, and (ii) $\partial^{2} \Omega_{j} / \partial w_{j} \partial n=\partial^{2} \Pi_{j} / \partial w_{j} \partial n+\beta_{j} \partial^{2} U_{j} / \partial w_{j} \partial n \leq 0$. Then our $n$-firm bargaining game shows strategic complementarity and an increase in $n$ leads to lower wages. It follows that in oligopolistic industries with powerful unions and where wages are bargained for at the firm level, wages and concentration ratios are positively correlated. Therefore, competition policy may play a role in moderating unions' wage claims and in restraining cost-push infiation.

Suppose that condition (i) above still holds but now take $\partial^{2} \Omega_{j} / \partial w_{j} \partial n \geq$ 0 . Then, we obtain the paradoxical result that equilibrium wages are larger, the larger the number of firms in the market. The intuition is that as $n$ increases the payoff associated with a wage cut (a marginal increase in firms' 
efficiency) falls. (A similar result is obtained by Martin (1993) in a completely unrelated model, featuring incomplete information and separation between ownership and control.)

\subsection{SINGLE-UNION BARGAINING}

So far we have only analyzed a totally uncoordinated wage bargain. We now briefly discuss the outcomes of more coordinated bargaining processes. For this purpose, it is useful to realize that unions may find it easier to collude than managers. In both cases there are clear incentives to collude: managers (unions) would like to internalize the negative (positive) externality they create on each other when choosing wage levels.

Since unions' objectives are not in conflict, as they all benefit from simultaneous wage increases at their corresponding firms, collusive agreements among them should naturally arise to avoid potential coordination failures. In principle, all that is needed is that unions communicate with each other to coordinate their bargaining strategies, since none of them will have an incentive to cheat once an agreement is reached. On the contrary, collusion among managers is unlikely to be sustainable. They could propose mutually taking into account the effects of their own wages on the competitor's profits at the bargaining stage. But even if this proposal was initially accepted, it would never be privately optimal to honor this agreement, because managers' objectives are in clear opposition. Indeed, each manager wants its rival to raise wages in order to undercut him and so win over some additional market share. Only an institution, like an employers' association, empowered to im- 
pose penalties or exclude deviators from other association-provided benefits, would be able to enforce the agreement.

Therefore, we should expect that managers fail to coordinate their strategies while unions succeed in taking into account the impact of their wage claims on other unions' welfare. ${ }^{22}$ In this case, firm $j$ 's objective function becomes $\tilde{\Omega}_{j}=\Pi_{j}+\beta_{j}\left(U_{j}+U_{i}\right), i \neq j$, and frm $j$ 's equilibrium wage, $w_{j}^{* *}$, solves:

$$
\partial \tilde{\Omega}_{j} / \partial w_{j}=\partial \Pi_{j} / \partial w_{j}+\beta_{j}\left(\partial U_{j} / \partial w_{j}+\partial U_{i} / \partial w_{j}\right)=0, \quad j=1,2 .
$$

From equations (9) and (12), and given that $\partial U_{i} / \partial w_{j}>0$ for all $w_{j}$, we have that $\partial \tilde{\Omega}_{j} / \partial w_{j}>0$ for $w_{j}=w_{j}^{*}$. Given that $\tilde{\Omega}_{j}$ is concave for the relevant $\beta_{j}$-range, it follows that $w_{j}^{* *} \geq w_{j}^{*}$, the equilibrium wage for the uncoordinated bargaining model, for all $j$. In addition, from (12) it should be clear that a manager facing a more powerful union than his competitor's would prefer single-union bargaining, while the opposite is true for the other manager. The intuition for this result is that single-union bargaining reduces wage differentials across firms.

If, in spite of our previous considerations, the managers of different firms also find a way to cooperate among themselves, so that industry wages are decided collectively among all unions and managers in the industry, firm $j$ 's equilibrium wage, $w_{j}^{c}$, maximizes the joint payoff function $\Omega_{1}+\Omega_{2}$, thus solving

$$
\partial \Pi_{j} / \partial w_{j}+\partial \Pi_{i} / \partial w_{j}+\beta_{j} \partial U_{j} / \partial w_{j}+\beta_{i} \partial U_{i} / \partial w_{j}=0, \quad j=1,2 .
$$

Since $\partial U_{i} / \partial w_{j}$ and $\partial \Pi_{i} / \partial w_{j}$ are both positive and $\beta_{j}$ and $\beta_{i}$ are such that $\Omega_{1}+\Omega_{2}$ is locally concave, then $w_{j}^{c} \geq w_{j}^{*}$ for all $j$. (Note that $w_{j}^{c}$ and $w_{j}^{* *}$ 
cannot be easily compared without additional assumptions on the parameters of the model.)

In conclusion, we have shown that, for a broad set of assumptions on the way coordinated bargaining is conducted, equilibrium wages are higher under coordination.

\section{CONCLUSIONS}

This paper contributes to a new strand of literature which emphasizes the strategic interactions that take place between wage-bargaining unions and employment-setting firms.

We have shown that the effects on equilibrium wages of various labor and product market characteristics depend on the strategic nature of the wage process. More precisely, the impact of those variables has been shown to depend on whether wages in different firms are strategic complements or substitutes (i.e., whether increases in one firm's wage lead to an increase or a decrease in other firms' wages), the former case being more likely the higher is the bargaining power of unions at the different firms.

Our analysis has yielded three main sets of results. First, we have departed from the symmetric setting, which characterizes most of the existing literature, in terms of bargaining strength, technology and demand. The symmetric setting precludes the investigation of several interesting cross-effects of unions, for which the strategic nature of wages matters crucially. Second, and most importantly, we have shown that the predictions of models which ignore strategic interactions or that assume overall strategic complementar- 
ity can be overturned. For example, increased productivity in one firm may lead to lower, not.higher, wages in that firm; and an increase in a union's bargaining power at one firm may lead to lower wages at competing firms if wages are strategic substitutes.

Thirdly, extensions of the model have provided new results on several issues. For example, unions' bargaining power needs to reach a certain threshold to ensure that a decrease in product market competition will lead to higher wages. Also, we have shown that taking into account the different viewpoints of unions and managers regarding the strategic nature of the bargaining process helps us understand why unions may find it easier to collude than managers.

Lastly, this paper could shed light on the specification of wage equations in empirical work. From the previous results it is clear that, once strategic interactions among competing firms are recognized, variables such as the competitors' productivity or their employees' bargaining power should enter the standard insider-outsider wage equations at the firm or sectoral levels which are found in the literature. Moreover, our results suggest that standard measures of market power, like industry concentration ratios, could better capture the link between market power and wages if interacted with measures of workers' bargaining power. 


\section{APPENDIX 1. SOME USEFUL RESULTS}

\section{Result 1: Properties of $s_{j}$ and $U_{j}$}

From the definition of $s_{j}$ in equation (7) in the text we can distinguish three regions depending on the value of $\theta_{j}^{*}$ : Region $1\left(\theta_{j}^{*} \leq \underline{\theta}\right)$, Region $2(\underline{\theta}<$ $\left.\theta_{j}^{*}: \leq \bar{\theta}\right)$, and Region $3\left(\theta_{j}^{*}>\bar{\theta}\right)$. The value of $\theta_{j}^{*}$ is such that $N_{j}^{*}\left(\theta_{j}^{*}\right)=M_{j}$. This, using equation (5):

$$
\begin{gathered}
\theta_{j}^{*}=3 a_{j} M_{j}+2 \tilde{w}_{j}-\tilde{w}_{i}, \\
N_{j}^{*}(\theta)=\left(\theta-2 \tilde{w}_{j}+\tilde{w}_{i}\right) / 3 a_{j}
\end{gathered}
$$

Using equation (2) we have that:

$$
\begin{gathered}
(a) \partial U_{j} / \partial w_{j}=\left(\partial s_{j} / \partial w_{j}\right)\left(w_{j}-w^{a}\right)+s_{j} \\
(b) \partial U_{j} / \partial w_{i}=\left(\partial s_{j} / \partial w_{i}\right)\left(w_{j}-w^{a}\right) \\
(c) \partial^{2} U_{j} / \partial w_{j}^{2}=\left(\partial^{2} s_{j} / \partial w_{j}^{2}\right)\left(w_{j}-w^{a}\right)+2\left(\partial s_{j} / \partial w_{j}\right) \\
(d) \partial^{2} U_{j} / \partial w_{i} w_{j}=\left(\partial^{2} s_{j} / \partial w_{i} \partial w_{j}\right)\left(w_{j}-w^{a}\right)+\left(\partial s_{j} / \partial w_{i}\right)
\end{gathered}
$$

Therefore, we have the following cases:

Region 1: In this case $s_{j}=1$ and all derivatives with respect to its arguments are zero. Hence $(a)=1$ and $(b)=(c)=(d)=0$. 
Region 2: In this case:

$$
s_{j}=\frac{\bar{\theta}-\theta_{j}^{*}}{\Delta}+\int_{\underline{\theta}}^{\theta_{j}^{*}} \frac{N_{j}^{*}(\theta)}{M_{j} \Delta} d \theta
$$

Using Leibnitz's rule and noticing that $N_{j}\left(\theta_{j}^{*}\right)=M_{j}$, we get:

$$
\partial s_{j} / \partial w_{j}=\frac{1}{M_{j} \Delta} \int_{\underline{\theta}}^{\theta_{j}^{*}} \frac{\partial N_{j}^{*}(\theta)}{\partial w_{j}}=-2\left(\theta_{j}^{*}-\underline{\theta}\right) / \Psi_{j}<0
$$

where $\Psi_{j}=3 a_{j}^{2} M_{j} \Delta$.

Similarly,

$$
\begin{gathered}
\partial s_{j} / \partial w_{i}=\left(\theta_{j}^{*}-\underline{\theta}\right) \Psi_{i j}>0 \\
\partial^{2} s_{j}^{2} / \partial w_{j}^{2}=-4 / \Psi_{j}<0 \\
\partial^{2} s_{j}^{2} / \partial w_{i} \partial w_{j}=2 / \Psi_{i j}>0
\end{gathered}
$$

where $\Psi_{i j}=3 a_{i} a_{j} M_{j} \Delta$.

Given the previous derivatives we have that: $\operatorname{sign}(a)>(<) 0, \operatorname{sign}(b)>0$, $\operatorname{sign}(c)<0$, and $\operatorname{sign}(d)>0$.

Region 3: In this case:

$$
s_{j}=\int_{\underline{\theta}}^{\bar{\theta}} \frac{N_{j}^{*}(\theta)}{M_{j} \Delta} d \theta .
$$

Thus, using similar arguments as above, we get

$$
\begin{gathered}
\partial s_{j} / \partial w_{j}=-2(\bar{\theta}-\underline{\theta}) / \Psi_{j}<0 \\
\partial s_{j} / \partial w_{i}=(\bar{\theta}-\underline{\theta}) / \Psi_{i j}>0 \\
\partial^{2} s_{j} / \partial w_{j}^{2}=0 \\
\partial^{2} s_{j} / \partial w_{i} \partial w_{j}=0
\end{gathered}
$$

Therefore: $\operatorname{sign}(a)>(<) 0, \operatorname{sign}(b)>0, \operatorname{sign}(c)<0, \operatorname{sign}(d)>0$. 


\section{Result 2: Properties of $\Omega_{j}$}

From the definition of $\bar{\beta}_{j}$ we have that

$$
\bar{\beta}_{j}(\cdot, \cdot)=-\left(\partial^{2} \Pi_{j} / \partial w_{j}^{2}\right) /\left(\partial^{2} U_{j} / \partial w_{j}^{2}\right)
$$

so that for $\beta_{j}(.,)>.\bar{\beta}_{j}(.,),. \Omega_{j}$ is concave. Then, it can be shown that $\bar{\beta}_{j}(.,$. is decreasing in $w_{j}$. This is so since, from the chosen functional forms for $\Pi_{j}$ and $U_{j}$, we have that $\partial^{2} \Pi_{j} / \partial w_{j}^{2}$ is a constant and $-\partial^{2} U_{j} / \partial w_{j}^{2}$ is increasing in $w_{j}$.

Since $\bar{\beta}_{j}(.,$.$) is decreasing in w_{j}$ and $w_{j} \in\left[w^{a}, w_{j}^{+}\right]$, it follows that $\bar{\beta}_{j}(\cdot, \cdot) \in$ $\left[\bar{\beta}_{j}\left(\cdot, w_{j}^{+}\right), \bar{\beta}_{j}\left(\cdot, w^{a}\right)\right]$. Three cases may arise: (i) if $\beta_{j}>\bar{\beta}_{j}\left(\cdot, w^{a}\right)$, then $\Omega_{j}$ is globally concave; (ii) if $\beta_{j}<\bar{\beta}_{j}\left(\cdot, w_{j}^{+}\right.$), then $\Omega_{j}$ is globally convex; and, (iii) if $\beta_{j} \in\left[\bar{\beta}_{j}\left(\cdot, w_{j}^{+}\right), \bar{\beta}_{j}\left(\cdot, w^{a}\right)\right]$, by continuity there will always exist a value $\widehat{w}_{j} \in\left[w^{a}, w_{j}^{+}\right]$such that $\beta_{j}=\bar{\beta}_{j}\left(\cdot, \widehat{w}_{j}\right)$, which implies that $\Omega_{j}$ will be convex for $w_{j}<\widehat{w}_{j}$ and concave otherwise. Thus, for given $w_{i}$, if $\Omega_{j}$ is concave at $w^{a}$, it will be concave for all feasible values of $w_{j}$. Conversely, if $\Omega_{j}$ is convex at $w_{j}^{+}$, it will be convex for all feasible values of $w_{j}$. Finally, in the intermediate case, $\Omega_{j}$ will always be first convex and then concave (as in Figure 1).

\section{RESULT 3: Deriving the inequality $\beta_{j}^{*} \geq \bar{\beta}_{j}$}

From the definitions of the cut-off points $\bar{\beta}_{j}=\bar{\beta}_{j}\left(w_{i}, w_{j}\right)$ and $\beta_{j}^{*}=$ $\beta_{j}^{*}\left(w_{i}, w_{j}\right)$ in the three regions that characterize $s_{j}$ (see Result 1 ), we have:

$$
0=\partial^{2} \Pi_{j} / \partial w_{j}^{2}+\bar{\beta}_{j} \partial^{2} U_{j} / \partial w_{j}^{2}
$$




$$
=\frac{8}{9 a_{j}^{2}}+\bar{\beta}_{j}\left\{\begin{array}{lr}
0 & (\text { Region 1) } \\
-4\left(\theta_{j}^{*}-\underline{\theta}+w_{j}-w^{a}\right) / \Psi_{j} & (\text { Region 2) } \\
-4 \Delta / \Psi_{j} & (\text { Region 3) }
\end{array}\right.
$$

and

$$
\begin{aligned}
0 & =\partial^{2} \Pi_{j} / \partial w_{i} \partial w_{j}+\beta_{j}^{*} \partial^{2} U_{j} / \partial w_{i} \partial w_{j} \\
& =\frac{-4}{9 a_{i} a_{j}}+\beta_{j}^{*}\left\{\begin{array}{lr}
0 & \text { (Region 1) } \\
\left(\theta_{j}^{*}-\underline{\theta}+2\left(w_{j}-w^{a}\right)\right) / \Psi_{i j} & \text { (Region 2) } \\
\Delta / \Psi_{i j} & \text { (Region 3) }
\end{array}\right.
\end{aligned}
$$

Thus, we have the following three cases:

(i) In Region $1, \bar{\beta}_{j} \rightarrow \infty$ and $\beta_{j}^{*} \rightarrow \infty$, so there will only be corner solutions, which we disregard in the analysis.

(ii) In Region 2, we get from the previous expressions that:

$$
\beta_{j}^{*} / \bar{\beta}_{j}=\frac{2\left(\left(\theta_{j}^{*}-\underline{\theta}\right)+\left(w_{j}-w^{\alpha}\right)\right)}{\left(\theta_{j}^{*}-\underline{\theta}\right)+2\left(w_{j}-w^{\alpha}\right)}>1
$$

(iii) In Region 3, we get from the previous expression that:

$$
\beta_{j}^{*} / \bar{\beta}_{j}=2
$$

Therefore, in general we have $\beta_{j}^{*} \geq \bar{\beta}_{j}$.

RESUlT 4: Strategic complementarity in Region 3

In order to prove that for $w_{j} \in\left[w^{a}, w_{j}^{+}\right], \beta_{j} \geq \beta_{j}^{*}\left(w_{i}, w_{j}\right)$ for all feasible values of $w_{i}$ we proceed by contradiction. 
Let us assume that there exists a $\beta_{j}$ such that $\beta_{j}<\beta_{j}^{*}\left(w_{i}, w_{j}\right)$ and that $w_{j}^{*}$ is an interior sohition, namely, it satisfies the first-order conditions:

$0=\partial \Omega_{j} / \partial w_{j}=\left(\mu-2 \tilde{w}_{j}+\tilde{w}_{i}\right)\left(\beta_{j} / 3 M_{j} a_{j}-4 / 9 a_{j}\right)-\beta_{j} \Delta / \Psi_{j}\left(2 \tilde{w}_{j}+2\left(w_{j}-w^{2}\right)\right)$

with $\mu=E(\theta)=(\bar{\theta}+\underline{\theta}) / 2$, which is easily obtainable from the functional forms of $\Pi_{j}$ and $U_{j}$. Since the first and the third terms in parentheses are positive, it must be that the second term is also positive, i.e., $\beta_{j}>4 M_{j} / 3$. However, from Result 3 we know that in Region $3, \beta_{j}^{*}=4 M_{j} / 3$. Hence, if $\beta_{j} \leqslant \beta_{j}^{*}$ the requirement is not fulfilled and $w_{j}$ cannot be an interior solution, i.e., a contradiction.

\section{APPENDIX 2. NUMERICAL COMPUTATION OF EQUILIBRIA}

This appendix explains how we compute numerically the equilibrium values of $w_{i}$ and $w_{j}$. The functional forms we have chosen yield a quadratic firstorder condition for each firm. Any candidate interior equilibrium $\left(w_{i}^{*}, w_{j}^{*}\right)$ must jointly solve the following system of equations:

$$
B_{j} w_{j}^{2}+\left(C_{j}+D_{j} w_{i}\right) w_{j}+\left(E_{j} w_{i}^{2}+F_{j} w_{i}+G_{j}\right)=0 ; i \neq j, \quad i, j=1,2
$$

where:

$$
\begin{gathered}
B_{j}=3 / a_{j}^{2}, C_{j}=\left(6 a_{j} M_{j}-4 v_{j}+2 v_{i}-4 M_{j}(\bar{\theta}-\underline{\theta}) /\left(3 \beta_{j}\right)-2 w^{a} / a_{j}-2 \underline{\theta}\right) / a_{j}, \\
D_{j}=-2 /\left(a_{j} a_{i}\right), E_{j}=1 / 4 a_{i}^{2}, \\
F_{j}=\left(-3 a_{j} M_{j}+2 v_{j}-v_{i}+4 M_{j}(\bar{\theta}-\underline{\theta}) / 3 \beta_{j}+2 w^{a} / a_{j}+\underline{\theta}\right) / 2 a_{i}, \\
G_{j}=-H_{j} 3 M_{j}(\bar{\theta}-\underline{\theta}) / 2 \beta_{j},
\end{gathered}
$$


and,

$$
\begin{aligned}
H_{j}= & -\beta_{j}\left(9 a_{j}^{2} M_{j}-12 a_{j} M_{j} v_{j}+6 a_{j} M_{j} v_{i}+4 v_{j}^{2}-4 v_{j} v_{i}+v_{\imath}^{2}\right) /\left(6 a_{j} M_{j}(\bar{\theta}-\underline{\theta})\right) \\
& +\left(4 /\left(9 a_{j}\right)+\beta_{j}\left(2 w^{a} / a_{j}+\underline{\theta}\right) /\left(3 a_{j} M_{j}(\bar{\theta}-\underline{\theta})\right)\right) /\left(3 a_{j} M_{j}-2 v_{j}+v_{i}\right) \\
- & \beta_{j} \underline{\theta}\left(\underline{\theta} / 2-2 w^{a} / a_{j}\right) /\left(3 a_{j} M_{j}(\bar{\theta}-\underline{\theta})\right)-4\left((\bar{\theta}-\underline{\theta}) / 2+3 a_{j} M_{j}\right) /\left(9 a_{j}\right)+\beta_{j} .
\end{aligned}
$$

Numerically we compute the candidate equilibria by solving the first-order conditions using the software package Maple. Once a solution is found, we check that the candidate equilibrium wages are real numbers strictly above the alternative wage, which yield positive production levels in all states of nature, satisfy the local second-order conditions, and are such that no firm has an incentive to change its wage (taking the other firm's wage as given). Lastly, we check whether the equilibrium is stable.

The parameters underlying Figures 3 and 4 are as follows, for all $j: \bar{\theta}=$ $1600, \underline{\theta}=800, w^{a}=50000, M_{j}=2.5, v_{j}=0, a_{j}=100$; in Figure $3, \beta_{j}=4$, and $\beta_{j}=5$ in Figure 4 . 


\section{FOOTNOTES}

${ }^{1}$ There is a long list of studies using monopolistic competition à la DixitStiglitz which could be cited. Good examples are Blanchard and Kiyotaki (1987), and Layard et al. (1991).

${ }^{2}$ See, for instance, Pugel (1980) and Dickens and Katz (1987) for the US; Nickell and Wadhwani (1990) and Nickell et al. (1992) for the UK; and Bentolila and Dolado (1994) for Spain.

${ }^{3}$ For example, Clark and Oswald (1993) report survey evidence for the UK in which $86 \%$ of unions indicate that the level of employment is usually decided by the employer.

${ }^{4}$ The use of conjectural variations for comparative statics purposes, once very popular among oligopoly theorists, is now much questioned. As an instance of today's mainstream view, Shapiro (1989, p. 354), in bis survey on oligopoly theory in the Handbook of Industrial Organization, claims that "... the idea behind conjectural variations is logically flawed, and they cannot constitute a bona fide theory of oligopoly."

${ }^{5}$ For US empirical evidence on the importance of this phenomenon see, for instance, Flanagan (1976) and Mebra (1976).

${ }^{6}$ Both this sequence of play and the implicit assumption that the parties bargain without knowing the bargaining outcome at the rival frm seem to be empirically supported (see Svejnar, 1986).

${ }^{7}$ Suppose that the union's bargaining objectives are decided by voting using a simple majority rule. Then, the union's objective function is given 
by the preferences of its median member. But given that workers are risk neutral and that layoffs are assigned randomly, the preferences of the latter coincide with the preferences of any other union member (see Layard et al., 1991, chapter 2).

${ }^{8}$ Firm j's laid-off workers join the pool of unemployed, which is assumed to be large enough so that the probability of being employed by firm $i, i \neq j$, in the current period is negligible. Hence, search considerations are ignored for simplicity.

${ }^{9}$ Unemployment may exist in this economy due to, for instance, matching frictions.

${ }^{10}$ Alternatively, we might have assumed $\Omega_{j}$ to be equal to $\Pi_{j}\left(U_{j}\right)^{\beta_{j}}$ (the Nash maximand), as is standard in the related literature on wage bargaining. This solution concept has been used extensively, because it can be derived as the subgame perfect equilibrium of a non-cooperative game of alternating offers (see Binmore et al. (1986) and Davidson (1988)). From an axiomatic point of view, our solution concept only differs from the Nash maximand in that it does not satisfy the axiom of invariance to affine transformations. (Both solution concepts satisfy the axioms of independence of irrelevant alternatives and Pareto efficiency.) But given that we assume that $\Pi_{j}$ and $U_{j}$ are defined in "monetary" terms, so that affine transformations of $\Pi_{j}$ and $U_{j}$ do modify the nature of the bargaining problem, the axiom of invariance to affine transformations is actually undesirable in our context.

11 We therefore ignore the strategic use of wage settlements in order to foreclose rivals in the product market (see Kühn (1994)).

12 That is, it is common knowledge that negotiations at the firm level 
satisfy equation (4), for all competing firms.

${ }^{13}$ This result holds in the absence of efficiency wage considerations, which could be introduced by making productivity, $a_{j}$, to depend on equilibrium wages.

${ }^{14}$ It can be easily shown that managers regard wages as strategic substitutes irrespectively of whether they set quantities or prices ex post. (A formal proof of this statement can be obtained from the authors upon request.)

${ }^{15} \theta_{j}^{*}$ is uniquely determined since, for all $j, N_{j}(\theta)$ is strictly increasing for all $\theta$, and $M_{j}$ is constant.

${ }^{16} w_{j}^{+}\left(w_{i}^{+}\right)$is the maximum wage level that can be paid by firm $j(i)$ without going bankrupt. We have already shown that this is equivalent to having non-negative production levels at $\underline{\theta}$. Thus, for a given $\tilde{w}_{j}, q_{i}^{*}\left(w_{1}, w_{2} ; \underline{\theta}\right) \geq 0$, implies that $\tilde{w}_{i} \leq\left(\underline{\theta}+\tilde{w}_{j}\right) / 2$. At the same time, $q_{j}^{*}\left(w_{1}, w_{2} ; \underline{\theta}\right) \geq 0$ implies that $\tilde{w}_{j} \leq\left(\underline{\theta}-\widetilde{w}_{i}\right) / 2 \leq\left(\underline{\theta}-\widetilde{w}_{j}\right) / 4$, from the previous inequality. Hence it must be that $\widetilde{w}_{j} \leq \underline{\theta}$. Since $\widetilde{w}_{j} \equiv w_{j} / a_{j}-v_{j}$, the latter inequality implicitly defines $w_{j}^{+}$.

${ }^{17}$ See Clark (1984), Ruback and Zimmerman (1984), Salinger (1984), and Abowd (1989).

${ }^{18}$ Note that condition (i) alone is not sufficient, because the lack of quasiconcavity of $\Omega_{j}$, and also that we do not need to consider deviations to any $w_{j}>w^{a}$, given the overall shape of $\Omega_{j}$ (see Figure 1 and Result 2 in Appendix $1)$.

19 The parameter values underlying these figures and the calculation method followed to derive them are contained in Appendix 2.

${ }^{20}$ Any interior equilibrium $\left(w_{1}^{*}, w_{2}^{*}\right)$ is stable if and only if, at this point 
and for all $i, j,\left|\partial^{2} \Omega_{j} / \partial w_{j}^{2}\right|-\left|\partial^{2} \Omega_{j} / \partial w_{j} \partial w_{i}\right| \geq 0$. This difference is continuous and monotonically increasing in $\beta_{j}$, strictly negative at $\bar{\beta}_{j}\left(w_{1}^{*}, w_{2}^{*}\right)$, and strictly positive at $\beta_{j}^{*}\left(w_{1}^{*}, w_{2}^{*}\right)$. Hence, there exists a $\hat{\beta}_{j}\left(w_{1}^{*}, w_{2}^{*}\right) \in$ $\left(\bar{\beta}_{j}\left(w_{1}^{*}, w_{2}^{*}\right), \beta_{j}^{*}\left(w_{1}^{*}, w_{2}^{*}\right)\right)$, such that if $\beta_{j} \geq \widehat{\beta}_{j}\left(w_{1}^{*}, w_{2}^{*}\right)$, the equilibrium is stable.

21 Given our assumptions on the product market (section 2.1), it is a standard result that firms' price-cost margins fall as the number of firms operating in the market rises. (See, e.g., Tirole, 1988, chapter 5.)

22 This is identical to assuming that there is a single union per industry, whose members are the insiders of firms 1 and 2, and which bargains separately with each firm's manager. 


\section{REFERENCES}

Abowd, J., 1989, "The Effect of Wage Bargains on the Stock Market Value of the Firn", American Economic Review, 79, 774-800.

Bentolila, S. and J. Dolado, 1994, "Labour Flexibility and Wages: Lessons from Spain", Economic Policy, 18, 55-99.

Bismore, K., A. Rubinstein, and A. Wolinsky, 1986, "The Nash Bargaining Solution in Economic Modeling", RAND Joumal of Economics, 17, 176-88.

Blanchard, O. and N. Kiyotaki, 1987, "Monopolistic Competition and the Effects of Aggregate Demand", American Economic Review, 77, 64766.

Bulow, J., J. Geanakoplos and P. Klemperer, 1985, "Multimarket Oligopoly: Strategic Substitutes and Complements", Journal of Political Economy, 93, 488-511.

Clark, W., 1984, "Unionization and Firm Performance: The Impact on Profits, Growth and Productivity", American Economic Review, 74, 893-919.

Clark, A. and A. Oswald, 1993, "Trade Union Utility Functions: A Survey of Union Leader's Views", Industrial Relations, 32, 391-411. 
Davidson, C., 1988, "Multiunit Bargaining in Oligopolistic Industries", Journal of Labor Economics, 6, 397-422.

Dickens, W. and L. Katz, 1987, "Inter-Industry Wage Differences and Industry Characteristics". In K. Lang and J. Leonard, eds., Unemployment and the Structure of Labor Markets, New York: Basil Blackwell.

Dowrick, S., 1989, "Union-Oligopoly Bargaining", Economic Journal, 99, 1123-1142.

Dowrick, S., 1993, "Enterprise Bargaining, Union Organization and Wages", Economic Record, 69, 1123-1142.

Dowrick, S. and B. Spencer, 1994, "Union Attitudes to Labor Saving Innovation: When Are Unions Luddites?", Journal of Labor Economics, 12, 316-344.

Flanagan, R.S., 1976, "Wage Interdependence in Unionized Labor Markets", Brookings Papers on Economic Activity, 3, 635-674.

Kühn, K.-U., 1994, "Labour Contracts, Product Market Oligopoly, and Involuntary Unemployment", Oxford Economic Papers, 46, 366-384.

Layard, R., S. Nickell, and R. Jackman, 1991, Unemployment, Macroec'onomic Performance and the Labor Market, Oxford: Oxford University Press.

Martin, R., 1992, Bargaining Power, Oxford: Clarendon Press. 
Martin, S., 1993, "Endogenous Firm Efficiency in a Cournot PrincipalAgent Model", Journal of Economic Theory, 59, 445-450.

Mehra, Y., 1976, "Spillovers in Wage Determination in US Manufacturing Industries", Review of Economics and Statistics, 58, 300-312.

Metcalf, D., 1993, "Industrial Relations and Economic Performance", British Journal of Industrial Relations, 31, 255-283.

Nickell, S., J. Vainiomaki and S. Wadhwani, 1994, "Wages, Unions, Insiders and Product Market Power", Economica, 61, 457-474.

Nickell, S. and S. Wadhwani, 1990, "Insider Forces and Wage Determination", Economic Joumal, 100, 496-509.

Pugel, T., 1980, "Profitability, Concentration and the Interindustry Variation in Wages, Review of Economics and Statistics, 62, 248-53.

Ruback, R. and M. Zimmerman, 1984, "Unionization and Profitability: Evidence from the Capital Market", Joumal of Political Economy, 92, 1134-1157.

Salinger, M., 1984, "Tobin's q, Unionization and the Concentration-Profits Relationship", RAND Journal of Economics, 15, 159-170.

Santoni, M., 1994, "Union-Oligopoly Sequential Bargaining: Trade and Industrial Policies", University of York, mimeo (forthcoming in Oxford Economic Papers). 
Shapiro, C., 1989, "Theories of Oligopoly Behavior". In R. Schmalensee and R. Willig, eds., Handbook of Industrial Organization, v. 1, Amsterdim: North-Holland.

Svejnar, J., 1986, "Bargaining Power, Fear of Disagreement and Wage Settlements: Theory and Evidence for US Industry", Econometrica, 54, 1055-1078.

Tirole, J., 1988, The Theory of Industrial Organization, Cambridge, MA: The MIT Press. 


\section{WORKING PAPERS (1)}

9525 Aurora Alejano y Juan M. ${ }^{2}$ Peñalosa: La integración financiera de la economía española: efectos sobre los mercados financieros y la política monetaria.

9526 Ramón Gómez Salvador y Juan J. Dolado: Creación y destrucción de empleo en España: un análisis descriptivo con datos de la CBBE.

9527 Santiago Fernández de Lis y Javier Santillán: Regímenes cambiarios e integración monetaria en Europa.

9528 Gabriel Quirós: Mercados financieros alemanes.

9529 Juan Ayuso Huertas: Is there a trade-off between exchange rate risk and interest rate risk? (The Spanish original of this publication has the same number.)

9530 Fernando Restoy: Determinantes de la curva de rendimientos: hipótesis expectacional y primas de riesgo.

9531 Juan Ayuso and María Pérez Jurado: Devaluations and depreciation expectations in the EMS.

9532 Paul Schulstad and Ángel Serrat: An Empirical Examination of a Multilateral Target Zone Model.

9601 Juan A yuso, Soledad Núñez and María Pérez-Jurado: Volatility in Spanish financial markets: The recent experience.

9602 Javier Andrés e Ignacio Hernando: ¿Cómo afecta la inflación al crecimiento económico? Evidencia para los países de la OCDE.

9603 Barbara Dluhosch: On the fate of newcomers in the European Union: Lessons from the Spanish experience.

9604 Santiago Fernández de Lis: Classifications of Central Banks by Autonomy: A comparative analysis.

9605 M. ${ }^{a}$ Cruz Manzano Frías y Sofia Galmés Belmonte: Credit Institutions' Price Policies and Type of Customer: Impact on the Monetary Transmission Mechanism. (The Spanish original of this publication has the same number.)

9606 Malte Krïger: Speculation, Hedging and Intermediation in the Foreign Exchange Market.

9607 Agustín Maravall: Short-Term Analysis of Macroeconomic Time Series.

9608 Agustín Maravall and Christophe Planas: Estimation Error and the Specification of Unobserved Component Models.

9609 Agustín Maravall: Unobserved Components in Economic Time Series.

9610 Matthew B. Canzoneri, Behzad Diba and Gwen Eudey: Trends in European Productivity and Real Exchange Rates.

9611 Francisco Alonso, Jorge Martínez Pagés y María Pérez Jurado: Weighted Monetary Aggregates: an Empirical Approach. (The Spanish original of this publication has the same number.)

9612 Agustín Maravall and Daniel Peña: Missing Observations and Additive Outliers in Time Series Models.

9613 Juan Ayuso and Juan L. Vega: An empirical analysis of the peseta's exchange rate dynamics.

9614 Juan Ayuso Huertas: Un análisis empírico de los tipos de interés reales ex-ante en España.

9615 Enrique Alberola Ila: Optimal exchange rate targets and macroeconomic stabilization. 
9616 A. Jorge Padilla, Samuel Bentolila and Juan J. Dolado: Wage bargaining in industries with market power.

(1) Previously published Working Papers are listed in the Banco de España publications catalogue.

Queries should be addressed to: Banco de España Sección de Publicaciones. Negociado de Distribución y Gestión Telephone: 3385180 Alcalá, 50. 28014 Madrid 